Georgia State University

ScholarWorks @ Georgia State University

Winter 12-15-2016

\title{
Can a Code of Ethics Reduce Sabotage and Increase Productivity under Tournament-Based Compensation? An Experimental Study
}

Stuart Smith

Follow this and additional works at: https://scholarworks.gsu.edu/accountancy_diss

\section{Recommended Citation}

Smith, Stuart, "Can a Code of Ethics Reduce Sabotage and Increase Productivity under Tournament-Based Compensation? An Experimental Study." Dissertation, Georgia State University, 2016.

doi: https://doi.org/10.57709/9453300

This Dissertation is brought to you for free and open access by the School of Accountancy at ScholarWorks @ Georgia State University. It has been accepted for inclusion in Accountancy Dissertations by an authorized administrator of ScholarWorks @ Georgia State University. For more information, please contact scholarworks@gsu.edu. 
Can a Code of Ethics Reduce Sabotage and Increase Productivity under Tournament-Based Compensation? An Experimental Study

BY

Stuart Manito Smith

A Dissertation Submitted in Partial Fulfillment of the Requirements for the Degree

Of

Doctor of Philosophy

In the Robinson College of Business

Of

Georgia State University 
GEORGIA STATE UNIVERSITY

ROBINSON COLLEGE OF BUSINESS

2016 


\section{Copyright by}

Stuart Manito Smith

2016 


\section{ACCEPTANCE}

This dissertation was prepared under the direction of the Stuart Manito Smith Dissertation Committee. It has been approved and accepted by all members of that committee, and it has been accepted in partial fulfillment of the requirements for the degree of Doctor of Philosophy in Business Administration in the J. Mack Robinson College of Business of Georgia State University.

Richard Phillips, Dean

DISSERTATION COMMITTEE

Douglas E. Stevens (Chair)

Michael J. Majerczyk

Ivo D. Tafkov

Jeffrey Hales 
ABSTRACT

Can a Code of Ethics Reduce Sabotage and Increase Productivity under Tournament-Based Compensation? An

Experimental Study

BY

Stuart Manito Smith

$07 / 23 / 2016$

Committee Chair:

Douglas E. Stevens

Major Academic Unit:

College of Accountancy

Managers have often used tournament incentive programs because of their ability to attract top talent and motivate employees to give their best effort (Grote 2005; McGregor 2006; Ng and Lublin 2010). However, because a tournament incentive structure explicitly evokes competition, prior economic literature has shown that the harmful effects of sabotage observed during a tournament can completely negate any benefits they have (Carpenter et al. 2010). The remedies suggested to reduce sabotage involve reducing the economic incentives that contribute to both beneficial and harmful behavior (Chen 2003). In the accounting literature to date, no remedy for the harmful effects of a tournament incentive has been investigated because the ability to sabotage has been restricted by way of tight experimental control. I utilize an experiment in which participants perform a real effort task which allows them to sabotage each other and receive relative performance feedback in real-time. I first predict that sabotage during a tournament will be higher than fixed pay because of the higher incentive to sabotage during a tournament. I then predict that by employing a code of ethics, I can activate the social norm of promise keeping which discourages those in a tournament from engaging in sabotage, while still giving their best effort. In the majority of cases, this allows the company to reap the previously observed benefits of a tournament incentive, while minimizing the previously observed costs that normally accompany a tournament incentive. However, I unexpectedly discover that a code of ethics can be able double-edge sword; In so much that, if violations persist despite certifications to follow the code, participants may become more discouraged and their behavior more detrimentally effects productivity than if those same violations occurred without a code. The implications of employing a code of ethics under these two incentive systems on overall productivity is explored.

Keywords: sabotage; tournament; code of ethics; social norm activation. 



\section{INTRODUCTION}

A rank-order tournament compensation scheme is one in which the pay, promotion, or prize depends on an individual's ordinal rank in the organization rather than his output level (Lazear and Rosen 1981a). Managers have often used tournament incentive programs because of their ability to attract top talent and motivate employees to give their best effort (Grote 2005; McGregor 2006; Ng and Lublin 2010). Tournaments help reduce the common uncertainty between employee effort and observable output by comparing employees to their peers, rather than tying compensation to a discrete measure of output (Lazear and Rosen 1979). This may reduce the required risk premium demanded by employees, which combined with their higher effort may lead to greater profits for the firm (Prendergast 1999). However, because the incentive structure explicitly evokes competition, employees may be reluctant to cooperate and might even engage in strategic behavior such as sabotage (Lazear 1989; Harbring and Irlenbusch 2011; Dato and Nieken 2014), excessive risk taking (Hannan et al. 2008) or other behavior that is incongruent with firm goals (Charness et al. 2014). For example, members of a sales division might not only refuse to share leads with or give advice to their colleagues, but also might poach clients or subvert client relationships while in a tournament. In addition, those who feel that victory is unattainable may simply become disheartened, "give up" and provide less effort than they would otherwise (Berger et al. 2013; Newman and Tafkov 2014). For this reason, companies may be reluctant to use tournament incentive programs when they need to motivate a large group of employees to not only give more effort, but also engage in sharing and cooperation. This study examines whether a combination of economic incentives and social norms can motivate employees to give their best effort without resorting to harmful strategic behavior like sabotage. 
Because only relative performance matters in a tournament, sabotage, rather than fidelity, may better serve the employee's interests. This means that under a tournament incentive scheme overall productivity may suffer because employees are willing to sabotage each other in order to win the tournament prize (Chen 2003; Münster 2007; Harbring and Irlenbusch 2005). This economic incentive for employees to engage in sabotage under a tournament incentive scheme may prove so detrimental to an employer's bottom line that they would have been better off utilizing a flat wage or piece rate incentive (Carpenter et al. 2010). Researchers in the economics and management literature have proposed several remedies to reduce sabotage from promotion based on seniority (Chen 2003) or a reduction in the prize spread (Harbring and Irlenbusch 2005) to gender quotas (Dato and Nieken 2014). Although they may reduce sabotage, previously proposed solutions may be costly and could reduce the benefits previously observed under a tournament incentive. I propose a different solution. Instead of adjusting formal controls by tweaking economic incentives, managers can rely on an informal control. They can utilize social norms by presenting the employees an opportunity to agree to a code of ethics that specifically condemns sabotage.

Recent accounting research has illustrated that getting employees to internalize to a code of ethics may activate social norms that can discourage undesirable behavior. By utilizing Bicchieri's (2006) model of social norm activation Davidson and Stevens (2013) predict and find that if managers publicly certify a code of ethics, both manager return behavior and investor confidence increase. If activating social norms discourages those in a tournament incentive program from engaging in sabotage while still giving their best effort, it may be possible for managers to get the "best of both worlds". In addition, those who would have been discouraged by sabotage and otherwise given up in a tournament might be encouraged to continue. Using 
Bicchieri's model in this study allows for relevant and verifiable predictions. Therefore, instead of simply reporting behavior that departs from traditional economic self-interest, this study helps us understand what drives such behavior.

Sabotage has been studied in economics and management and has been acknowledged as a problem in accounting (Bol and Lill 2015), but the ability to engage in such behavior has largely been controlled in experimental accounting studies. By allowing employees to personally gain at the expense of one another, I specifically examine a very attractive form of sabotage: overtly stealing credit from fellow employees. This often takes place in the workplace and can affect raises and promotion decisions (Uzzi and Dunlap 2012; Dillon 2014). I chose to study this attractive form of sabotage because any remedy I found would also presumably work on less attractive, more self-destructive forms of sabotage. I make two theoretical predictions. First, based on the economic incentives present in a tournament and the results of prior experimental studies, I predict that sabotage will be higher under a tournament incentive than a flat wage incentive. Second, if participants first certify a code of ethics that discourages sabotage, I predict an interaction will occur whereby the decrease in sabotage will be highest under a tournament incentive. This prediction is based on the expectation that the certification of the code of ethics activates social norms, such as promise keeping, which lead to a decrease in sabotage. This decrease will be highest under a tournament because it's easier to rationalize bad behavior (and thus evade the norm) under a flat wage compensation because (unlike under a tournament) sabotage doesn't lead to economic harm. Finally, I explore interactive effects of incentive type and code of ethics certification on overall productivity.

I ran an experiment with a $2 \times 2$ between-subjects factorial design (with repeated periods). I manipulated the presence or absence of a code of ethics (that condemns sabotage) and the type 
of incentive compensation used (tournament / flat wage) to examine their effects on individual employee behavior and overall firm productivity. Groups of three participants engage in a real effort task entitled Stamp Out!, a task featured in the videogame Mario Party 4 (Nintendo 2002). Each of the three active participants simultaneously attempts to "paint" as much of single large canvas as they can in 30 seconds. Each participant controls a "stamp" with a unique color that begins the round at a different part of the canvas. When the timer starts, all participants can witness each other's activity in real-time while a countdown timer is displayed at the top of the screen. If they choose, participants have the ability to benefit from sabotage by painting over a section of the canvas that has already been covered with another participant's unique color. At the end of a 30 second round, each participant is shown what percentage of the total canvas has been covered in their unique color. Participants are compensated based on a rank order or a flat wage. Participants repeat the activity for ten rounds and then answer a post-experimental questionnaire.

The results of the experiment support my two predictions, that sabotage is more likely to occur during a tournament and that a code of ethics would lead to the greatest reduction in sabotage during a tournament. However, I find that employing a code of ethics during a tournament might not always be best for productivity. Although, in the majority of cases certifying a code of ethics nearly eliminated sabotage entirely, which led to high productivity, in the few cases in which sabotage occurred despite a code of ethics the other participants were so discouraged they appeared to give up entirely.

The study makes several contributions to the accounting literature. First, because I utilized a real effort task that "involves effort, fatigue, boredom, excitement and other affectations not present" in chosen effort (van Dijk et al. 2001, 189), I was able to capture 
behavior and gain insights that may not have been possible had I followed the traditional method of using a turn-based effort choice task. I also discovered a relatively low cost way to reduce sabotage and that was shown to be effective in environments where sabotage was most likely to occur. In addition, I might be able to shed some light on how the effectiveness of different compensation schemes (like those presented in Hannan et al (2008) and Tafkov (2013) compare when given timely relative performance feedback and sabotage $i s$ allowed. I also extend prior literature by further exploring the underlying mechanisms that manage Bicchieri's model of social norm activation.

This study also has potential implications for practice by providing management with insight into how to practically design and implement an incentive system. Although acts of overt sabotage, like stealing ideas or taking credit for the work of others can happen in even the most cohesive and familial environments, the game-like nature of the environment used in this study most closely matches workplace environments that highly prize individual achievement and focus workplace monitoring on the results rather than the mechanisms of employee behavior. Specific examples may include that of a Car Sales Consultant who have been described as working in a "cut-throat environment", which may contribute to the $72 \%$ annual turnover rate (NADA 2015). The fact that sabotage was affected at all, in an environment where there were such strong economic and social incentives that encourage unethical behavior toward fellow employees, speaks to the potential power of this relatively simple remedy. However, this study also sheds light on the fact that while employing a code of ethics can be an economical and effective tool; I find it possible that it can also be a double-edged sword if its efficacy is not monitored. 
In the next section, I give a short review of the relevant literature and develop my hypothesis. In Section III, I describe my experimental design. In Section IV, I present my results. In Section V, I conclude.

\section{LITERATURE REVIEW AND HYPOTHESIS DEVELOPMENT}

\section{Tournaments}

Lazear and Rosen (1981) present an early formal theoretical model for behavior in rankorder tournaments. In their model, output is observable and input is not. Output is described as a function of both effort and noise, such that: Output $=$ Effort + Noise. Noise consists of both common environmental factors and individual idiosyncratic factors that are beyond the control of the employee. Because employees are assumed to be risk averse, they demand a risk premium under a piece-rate contract (Lazear and Rosen 1981a). However, under a tournament incentive scheme where employees are rewarded based on relative rank, the common environmental risk is

shared by all employees. This largely reduces the need for a risk premium because pay would be independent of these common environmental factors (Hannan et al. 2008). Assuming that there isn't a large disparity in skill level among the employees, tournaments are generally regarded as a suitable means to increase effort and performance (Lazear and Rosen 1981a).

Tournaments are largely observed in practice with prizes ranging from a simple promotion to large cash bonuses or extravagant vacation packages (Casas-Arce and MartínezJerez 2009; Backes-Gellner and Pull 2013). Over half of US companies utilize some form of a tournament incentive scheme, which leads some employees to add value to the firm (McGregor 2006). However, because a tournament incentive explicitly evokes competition, some employees might engage in counter-productive strategic behavior such as a sabotage (Lazear 1989; Harbring 
and Irlenbusch 2011; Dato and Nieken 2014), excessive risk taking (Hannan et al. 2008) or other behavior that is incongruent with firm goals (Charness et al. 2014).

\section{Sabotage}

In this study, I examine one of the most attractive forms of sabotage: overtly stealing from fellow employees. This form of sabotage is attractive because the saboteur directly benefits in absolute terms as well as in relative terms. Overtly stealing credit for a fellow employee's idea or past effort can even be used when competition among fellow employees isn't very salient, such as when the reward is a simple praise from a superior or increases the possibility of a promotion (Dillon 2014). Many times this type of sabotage is hard to guard against, especially during collaborative work where management doesn't have the will and/or resources to know who did what (Uzzi and Dunlap 2012). It may also be hard to combat because it could be engrained in workplace culture such as when union leaders commandeer money-saving workplace improvements from low-level union members, pass them onto management, and collect the reward for themselves (Gupta and Singhal 1993).

However, not all forms of sabotage benefit the saboteur, in absolute terms (Crino 1994, 312) defined workplace sabotage as behavior intended to "damage, disrupt, or subvert the operations for the personal purposes of the saboteur by creating unfavorable publicity, embarrassment, delays in production, damage to property, the destruction of working relationships, or the harming of employees or customers". Other examples of sabotage can range from gossip and bullying to theft or destruction of files or equipment (Sprouse and IllustratorCox 1992; Jeter and Nursing 2010; Maher 2010). Additionally, motivations behind sabotage can vary from social injustice to simple economic incentives and can be targeted at either individuals or the organization itself (Analoui 1995; Ambrose et al. 2002). Workplace sabotage can 
adversely affect not only the physical and psychological health of one or more individuals, but also the overall productivity and financial health of the organization as a whole (Jeter and Nursing 2010). Because of its impact and prevalence in the modern workforce, sabotage is considered an important subject of examination by researchers in both economics and management.

Using an economic model, Chen (2003) illustrated that employees in competition for promotion (a type of rank-order tournament) would generally focus their sabotage on the member with the greatest ability. As an old Japanese proverb says, "the nail that sticks out gets hammered" (Okada 1955, 28). This not only leads to productive inefficiencies, but also decreases the chance that the most competent employees get promoted (Chen 2003). This phenomenon has since been observed in subsequent experimental studies (Münster 2007; Carpenter et al. 2010). In fact, when sabotage was allowed within a tournament incentive scheme, the advantages previously observed over a piece rate scheme were lost (Carpenter et al. 2010).

Prior economic research has also shown that certain factors can moderate the amount of sabotage in a tournament. A handful of experiments have found that sabotage increases as the prize spread in the tournament increases and serve as a reminder of the power of traditional explicit economic incentives (Harbring and Irlenbusch 2005; Harbring and Irlenbusch 2008; Harbring and Irlenbusch 2011). Researchers have also observed this phenomenon in practice. del Corral et al. (2010) observed that an increase in the points awarded for a victory in fútbol tournament play affected the incidence of fouls, penalty cards, and the number of defensive players on the roster (del Corral et al. 2010). However, a more recent study highlights that implicit nonmonetary factors can also motivate individuals to engage in sabotage (Charness et al. 2014). Charness et al. (2014) placed participants into groups of three and gave them a flat wage 
to work on a decoding task. Simply providing relative performance information motivated the participants to invest in costly sabotage in order to improve their relative position in the group. The results of their study suggest that economic incentives are not necessary to persuade individuals to engage in sabotage. The status achieved through simple social comparison would be enough to motivate the participants to engage in sabotage, even if the task doesn't require any particular skill or talent.

Another set of studies imply that companies may not need to add any economic or social incentives in order to encourage sabotage (Abbink and Sadrieh 2009; Abbink and Herrmann 2011). In these studies, two players are endowed with an equal amount of money and simultaneously decide whether or not to "destroy" the other player's payoff for a price. The authors manipulate whether or not there is a one in three chance that an "act of nature" would destroy their opponent's money anyway. The authors find the destruction rates rise significantly during the aforementioned treatment ${ }^{1}$, despite the fact that no strategic reason exists for such a decision. This implies that some individuals simply take pleasure in destruction.

Even though employees may not need an overt economic incentive to engage in sabotage, it certainly does not hurt. Prior literature shows that workers compensated under a tournament incentive scheme are more likely to engage in sabotage than those under piece rate compensation (Carpenter et al. 2010). This is because those in a rank order tournament benefit the most economically from sabotage. Those being paid a flat wage receive no economic benefit at all from sabotage.

\footnotetext{
${ }^{1}$ If we view the results of this study in light of Bicchieri's (2006) model, the results seem to suggest that the participants were able to evade any social norms that would discourage destruction by hiding behind uncertainty not unlike the participants in Abdel-Rahim and Stevens (2015)
} 
Based on prior literature, simply having relative performance information provides enough social incentives to engage in sabotage regardless of whether employees are compensated via a tournament or flat wage. However, only tournament compensation provides a clear economic incentive to engage in sabotage. Therefore I expect that employees will engage in more sabotage when compensated under a tournament incentive system than given a flat wage.

\section{H1: Employees will engage in more sabotage when compensated under a tournament incentive system than given a flat wage}

Because of the harm that sabotage can have on productivity, researchers have suggested a variety of countermeasures. Some have proposed implementing a system that can identify and sanction such behavior (Balafoutas et al. 2012). Others have suggested reducing the economic incentives either by promoting based solely on seniority or instituting pay equality rather than tournament prizes (Chen 2003; Harbring and Irlenbusch 2008). Other proposals include gender quotas during promotion because of the disproportionate likelihood that males will engage in sabotage (Dato and Nieken 2014). In addition, others have proposed reducing the sting sabotage might have on productivity by eliminating relative performance information, which reduces the chance that others in the group will combine their efforts to sabotage the highest performer (Gürtler et al. 2013). It's worth noting that each of the previously proposed solutions is admittedly not without its drawbacks. Some would be either costly to implement (Balafoutas et al. 2012) or may reduce the positive effects tournaments may offer (Harbring and Irlenbusch 2008). For example, public relative performance information has been shown to have a positive effect on individuals under certain types of performance-based contracts (Tafkov 2013; Newman and Tafkov 2014). I propose a different solution. Managers can utilize social norms by 
presenting the employees an opportunity to agree to a code of ethics that specifically condemns sabotage.

\section{Code of Ethics}

Langlois and Schlegelmilch (1990 p. 522) define a corporate code of ethics as " a statement setting down corporate principles, ethics, rules of conduct, codes of practice or company philosophy concerning responsibility to employees, shareholders, consumers, the environment, or any other aspects of society external to the company.' Although a heightened research interest has followed the increased prevalence of corporate codes, most of the research has focused on the content of these codes rather than their effect on behavior (Benson 1989; Jamal and Bowie 1995; Stajkovic and Luthans 1997; Svensson et al. 2009; Bodolica and Spraggon 2015; Komic et al. 2015). Furthermore, those studies that focus on the effectiveness of a code of ethics seem to yield mixed results. Some researchers have found that organizations that utilize a code of ethics report a lower incidence of misconduct and rate their companies as more ethical (Pierce and Henry 1996; Schwartz 2001; Somers 2001; KPMG 2008). While other studies conclude that a code of ethics doesn't positively affect behavior and is simply a way to protect the company from legal liability (Stevens 1994; Cleek and Leonard 1998; McKendall et al. 2002; Helin and Sandstrom 2007). In a review of research that examines the effectiveness of a code of ethics in corporations, Kaptein and Schwartz (2008) attribute the mixed results to a lack of theory, deficiencies in research methodologies and an inconsistent definition of a code of ethics.

Watruba, Chonko, and Loe (2001) illustrate three major reasons why a company should adopt a code of ethics: (1) to show that they value ethical behavior; (2) to relay their ethical values to the members of their organization; and (3) to impact employee behavior (Wotruba et al. 2001). Over the last thirty years, there has been a sharp rise in the number of companies that 
have instituted a code of ethics/conduct within their organization (KPMG 2008). Ironically, the rise doesn't seem to be attributed to a crisis of conscious. According to KMPG, $85 \%$ of the Global 200 companies polled gave "compliance with legal requirements" as the primary reason for having a code of ethics. Section 406 of the Sarbanes-Oxley Act (SOX 2002) requires organizations to disclose the adoption of a corporate code of ethics or justify the absence of such a code. In addition, the New York Stock Exchange and NASDAQ now require all listed firms to adopt and disclose their corporate code of ethics. The motivation behind why an organization implements a code of ethics may be a major contributor to how effective it is. If employees perceive that a code of ethics merely exists to fulfill a legal requirement, then they may be less likely to (1) perceive that they company values ethical conduct; (2) know what the company values; and (3) develop expectations that influence their behavior.

More recently, other researchers have attempted to identify the specific determinants that make a corporate code of ethics successful after observing that the mere existence of a code of ethics may not be enough to affect behavior (Wotruba et al. 2001; Kaptein and Schwartz 2008; Singh 2011). Wotruba et al. (2001) surveyed nearly three hundred executives that were members of the Direct Selling Association. They found that effectiveness of the code of ethics was associated with familiarity and usefulness. Singh (2011) surveyed the CEOs of over one hundred of Canada's top 500 companies. He found that the effectiveness of the code of ethics was associated with its communication and perceived enforcement within the organization. Davidson and Stevens (2013) captured these two attributes by having participants "certify" the code of ethics. They utilized an investment game and found that a code of ethics improved manager return behavior and investor confidence only to the extent that it activated social norms that control opportunistic behavior. It wasn't until managers "certified" the code of ethics that these 
benefits were achieved. Further analysis revealed that the underlying mechanism driving their results was the activation of the social norm of promise keeping as predicted by Bicchieri's (2006) model of social norm activation (Davidson and Stevens 2013). As I explain below, social norm theory can also be used to predict the results of both Wotruba et al. (2001) and Singh (2011).

Social Norm Theory

As summarized in Blay et al. (2015) the roots of social norm theory can be traced back to Adam Smith's (1759/1790) influential work, The Theory of Moral Sentiments. Smith asserted that mankind is gifted with a natural reverence for the general rules of conduct. This natural respect for social norms can be observed in the substantial role that norms and laws play in sustaining order throughout society (Smith 1759/1790; Blay et al. 2015). Bicchieri’s (2006) model of social norm activation explains how people interpret the motives and expectations of others. Consistent with Adam Smith's (1759/1790) moral theory, the model suggests that social norm activation relies on situational cues and information that shape beliefs and expectations.

According to the Bicchieri model, first, there is a contingency condition. This condition is essential to the activation of a social norm. The contingency condition asserts that individuals are aware that a behavioral rule $\mathbf{R}$ exists and applies to situations of type $\mathbf{S}$. In other words, everyone has to know about the behavioral rule and its relevance to the current situation. Next, the Bicchieri model describes the empirical expectations condition. This is a belief that an adequately large subset of the population $\mathbf{P}$ conforms to the behavioral rule $\mathbf{R}$ in situations of type $\mathbf{S}$. These expectations are often based on observed behavior in similar situations and can be strengthened or weakened by the ensuing observed behavior. Finally, the Bicchieri model describes two normative expectations conditions. The first normative condition states that 
individuals believe an adequately large subset of $\mathbf{P}$ expects them to conform to $\mathbf{R}$ in situations of type $\mathbf{S}$. What makes the situation normative is that individual's perception of what other people believe that an individual has an obligation to confirm to $\mathbf{R}$ in the appropriate circumstances. The belief that others' normative expectations are reasonable or legitimate can be sufficient to motivate behavior consistent with a social norm. The second normative condition adds the belief that others may be willing to sanction the individual's behavior when they can observe it. This possibility of sanctions may be necessary for some individuals to follow a social norm. Bicchieri $(2006,45)$ also asserts that social norms are complex, and "several norms may apply to the same situation, or it may not be clear which norms have a bearing in a given case."' Simply publically agreeing to act "ethically" (as is the case in my study) may activate any number of social norms including fairness, reciprocity, and trustworthiness (in addition to the social norm of promisekeeping) (Bicchieri 2006).

In summary, her model suggests that a social norm is activated when a person is made aware of a behavioral rule that is relevant to the current situation (the contingency stage). That person will then follow that rule if he believes that there are both empirical and normative expectations that give him a sufficient reason to follow the behavioral rule. Bicchieri's model predicts the results of the surveys reported in both the Wotruba et al. (2001) and Singh (2011) studies. In their respective studies, communication and familiarity are both indicators that the employees will reach Bicchieri's contingency stage. Likewise, usefulness and enforcement are both indicators that the company has provided both empirical and normative expectations which lead to compliance with the norm within the organization. Bicchieri's model also empowers experimental researchers to develop testable hypotheses related to contextual factors on moral reasoning and behavior. For example, the effectiveness of a contextual factor (such as requiring 
certification of a code of ethics) is based on its ability to alter empirical and normative expectations for a given norm. I believe that by having every employee agree to sign a code of ethics, a company can provide both empirical and normative expectations that will lead the employee to keep their promise and adhere to the code (Bicchieri 2006; Davidson and Stevens 2013).

The Interaction of Economic Incentives and Social Norms

Initially, because none of the participants have been able to observe each other's behavior, a normative expectation (rather than an empirical expectation) would likely have the most influence over their behavior. In the presence of a certified code of ethics, a strong normative expectation is established (Davidson and Stevens 2013). In this study, the code of ethics is designed to discourage sabotage and encourage fidelity. As a result, I would expect the participants who certify a code of ethics to initially abstain from engaging in sabotage. In addition, immediately after the task begins, participants will start to develop an empirical expectation based on what they observe. Therefore, their initial observed fidelity should be reinforced by the subsequent observation of ethical behavior.

I expect that, absent a code of ethics, employees under tournament compensation would engage in more sabotage than employees given a flat wage (see H1). Therefore, if I expect a code of ethics can reduce sabotage at all, I would expect it to have a greater effect on those under a tournament incentive than those given a flat wage simply because those under tournament compensation have more room to improve. However, it is possible that because a code of ethics primes the employee to think of the possible harm (s)he could cause to others (rather than thinking solely about their own benefit), that those in a tournament might sabotage less than those given a flat wage (Tsang 2002). This is because sabotage during a tournament causes both 
social and economic harm to others, while sabotage under flat wage compensation does not cause any economic harm to others. Therefore, even though that a code of ethics primes employees to think of others regardless of condition, it is easier to rationalize bad behavior under a flat wage compensation because (unlike under a tournament) there is no economic harm. In any case, I predict that having employees certify a code of ethics will have a larger effect on sabotage for those under tournament based compensation than those under piece rate or flat wage compensation.

\section{H2: Having employees certify a code of ethics will have a larger mitigating effect on sabotage for those under tournament based compensation than those flat wage compensation.}

Effects on Overall Productivity

Overall Group Productivity can be simply defined as Group Effort-Group Effort Wasted due to Sabotage. Like sabotage, Group Effort can be influenced by both economic and social factors. Although the flat wage condition may lack an economic incentive to give effort, participants are given relative performance feedback in that they will be able to view each other's actions in real-time with a single winner being declared for each round. In the presence of relative performance information, even without economic incentives, individuals can be motivated to exert effort simply because they take joy in outperforming others. Evidence of simple social comparison motivating effort has appeared in psychology, economic and accounting literatures (Suls and Wills 1991; Hannan et al. 2008; Dohmen et al. 2011; Tafkov 2013; Newman and Tafkov 2014) and has even lead famous children's author C.S. Lewis to write: 
We say that people are proud of being rich, or clever, or good-looking, but they are not. They are proud of being richer, or cleverer, or better-looking than others. If everyone else became equally rich, or clever, or good-looking there would be nothing to be proud about. It is the comparison that makes you proud: the pleasure of being above the rest. Once the element of competition has gone, pride has gone (Lewis 1952, 81).

Therefore, I expect all participants, even those in the flat wage conditions, to put forth significant effort. By the same token, although tournaments provide employees a positive economic incentive to put forth more effort in order to outperform their colleagues, repeated tournaments can also be accompanied by negative social factors such as complacency by the winners and dejection by the losers (Berger et al. 2013). Therefore, because tournaments have been associated with both an increase in effort due to economic incentives and a decrease in effort due to discouragement, it is difficult to predict the effect of the economic incentive on group effort. This makes it difficult to predict the interactive effects on overall productivity. Likewise, it is difficult to predict the effects of a code of ethics on effort. Unlike sabotage, effort might not have much room for improvement.

However, if tournaments are accompanied by an increase in sabotage (as I predict in $\mathrm{H} 1$ ) then the effect of tournaments on Group Loss due to Sabotage (and therefore group productivity) is quite clear. The increase in sabotage that I predict will accompany a tournament incentive can lead to Group Loss in two ways, through discouragement and/or redundancy. In repeated periods, sabotage can be demoralizing and may lead to employees exerting less effort than they would otherwise. Sabotage also directly leads to Group Loss because of the redundancy of effort. For example, one member of a sales division might put forth a significant amount of effort in order to win over a client only to have another member of sales division go after the same client 
(rather than someone else) in an effort to steal his sale. In this case, had both members gone after separate clients, the company might have had twice as many sales with the same amount of collective effort. The effect of a code of ethics on Group Loss is discernable. Prior literature leads me to believe, that when workers certify a code of ethics that condemns sabotage, the activation of the social norm of promise keeping will discourage sabotage (Davidson and Stevens 2013).

Because Group Productivity is the difference between Group Effort and Group Loss and the effects of incentive compensation and a code of ethics on Group Effort is unclear, I pose the following research question in order to explore the effects these two factors have on overall productivity.

\section{RQ1: How will having employees certify a code of ethics affect the productivity of those under tournament based compensation versus those under a flat wage compensation?}

\section{METHODOLOGY}

\section{Experimental Task}

The participants are given instructions that explain that they had been hired by "Painter Corp" to paint a series of canvases. They are told that the goal of Painter Corp is to have as much of each canvas painted as possible. The computerized task is a modified version of a single minigame featured in the videogame Mario Party 4 (Nintendo 2002). In the mini-game, entitled Stamp Out!, four ${ }^{2}$ players, each sitting on top of a uniquely colored machine that resembles a

\footnotetext{
${ }^{2}$ During the experimental task, only three players are active. The fourth is an inactive host player who is controlled by the experimenter. This is detailed later on in the paper.
} 
pogo stick atop a stamp pad $^{3}$, simultaneously try to "paint" as much of a large single white canvas as they can in 30 seconds. All the participants witness each other's activity in real-time while a count-down timer is displayed at the top of the screen. At the end of a 30 second round, each player is shown what percentage of the total canvas has been covered in their unique color. Players control their stamp pad by manipulating five keys on their computer keyboard, namely the four directional arrow keys and " $\mathrm{X}$ " $\mathrm{key}^{4}$. Every time a player stamps the canvas, the spot on the canvas where the player has stamped is painted with their unique color. Therefore, it is possible that any one player can stamp over an area that was previously painted by another player. Stamping over a spot where another player has previously painted increased the amount of canvas that they are credited with painting while simultaneously decreasing the amount of canvas the other player is credited with painting. However, the canvas is large enough that each of the three active players has the opportunity to paint as much of the canvas as they are capable of without needing to paint over a colleague ${ }^{5}$. This fact is illustrated in Figure 1.

\footnotetext{
${ }^{3}$ The participants control a character that is sitting on top of a large rubber stamp filled with ink. Each time the participant presses the " $X$ " key, the character (while sitting on top of the stamp) can "hop" a certain distance along the white canvas thereby creating a new ink spot with the rubber stamp. The distance the character hops depends on the amount of time the participant holds down the " $\mathrm{A}$ " key. Each additional hop requires and additional pressing of the " $X$ " key. See Figure 1 for screenshots of the gameplay.

${ }^{4}$ The real effort task of attempting to paint as much of the canvas as possible by hopping on a rubber stamp captures all four components of the effort construct mentioned in (Bonner and Sprinkle 2002): direction, duration, intensity, and strategy development. (1) Direction: The employee may direct their avatar in any direction they choose (2) Duration: The employee may choose how long they want to engage in the activity (and they are also compensated for inactivity) (3) Intensity: it takes focus to precisely time the key strokes in order to quickly cover the most ground. Mindlessly mashing the " $A$ " will not result in the fastest movement. (4) Strategy: navigating the field of play and deciding if/when to engage in sabotage.

${ }^{5}$ In pre-trial testing, the maximum amount a very skilled player could paint in 30 seconds was $25 \%$ of the canvas. Similarly, during the experiment, the maximum amount that any participant could paint in 30 seconds was $25 \%$ of the canvas (two participants achieved this feat). The maximum amount that any group of participants could paint was $64 \%$ of the canvas.
} 


\section{Figure 1}

\section{Part A:}

\section{Screenshots of the Incentivized Task (with Sabotage)}

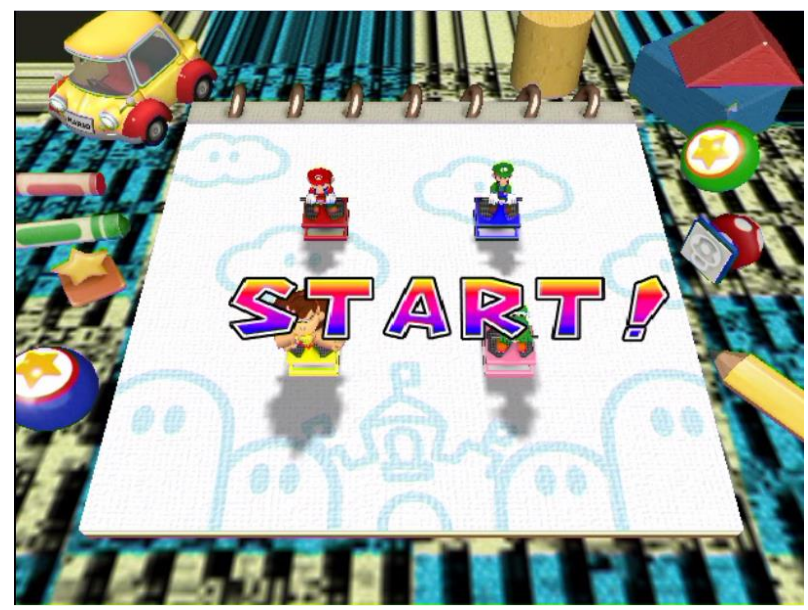

The participants start in the position seen above.

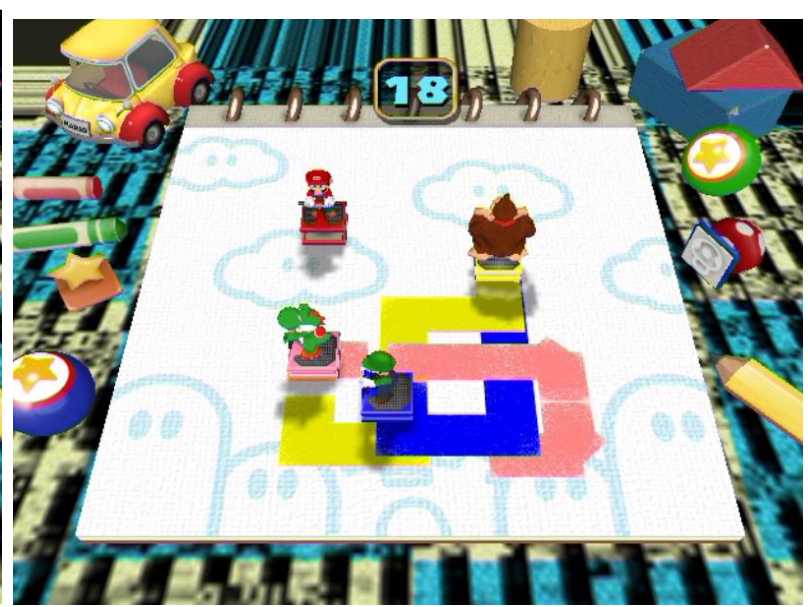

In the example above, all three active avatars can be seen actively engaging in sabotage

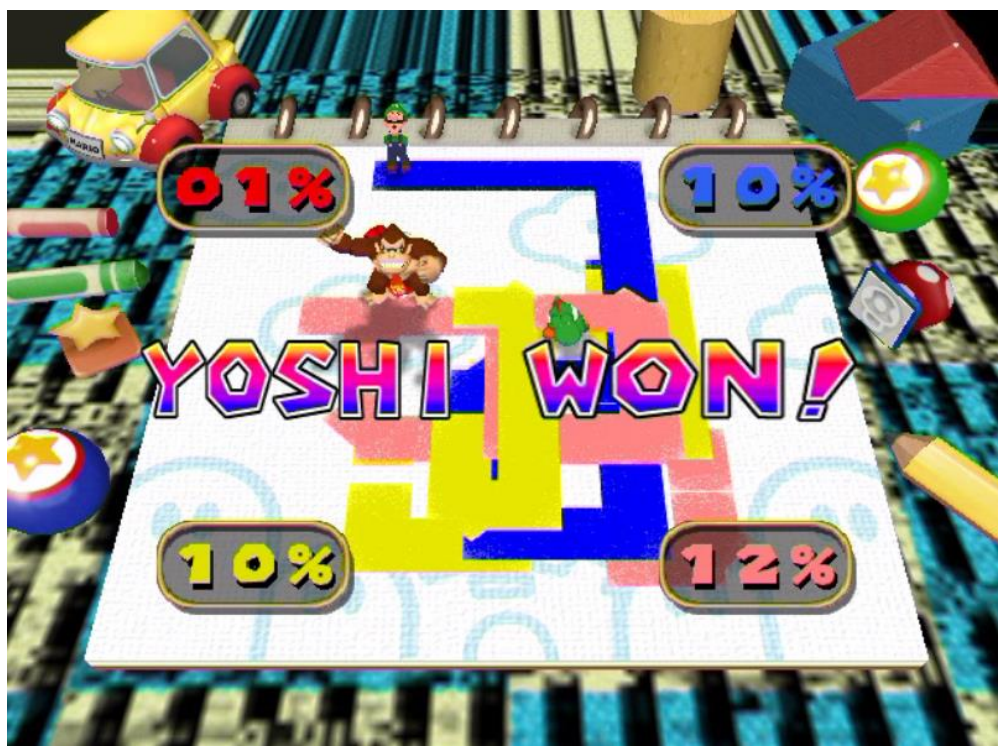

A total of $32 \%$ of the canvas was painted by the participants. The red avatar (Mario) was controlled by the host computer and was inactive throughout the experiment. 


\section{Figure 1 (continued)}

\section{Part B:}

\section{Screenshots of the Incentivized Task (without Sabotage)}

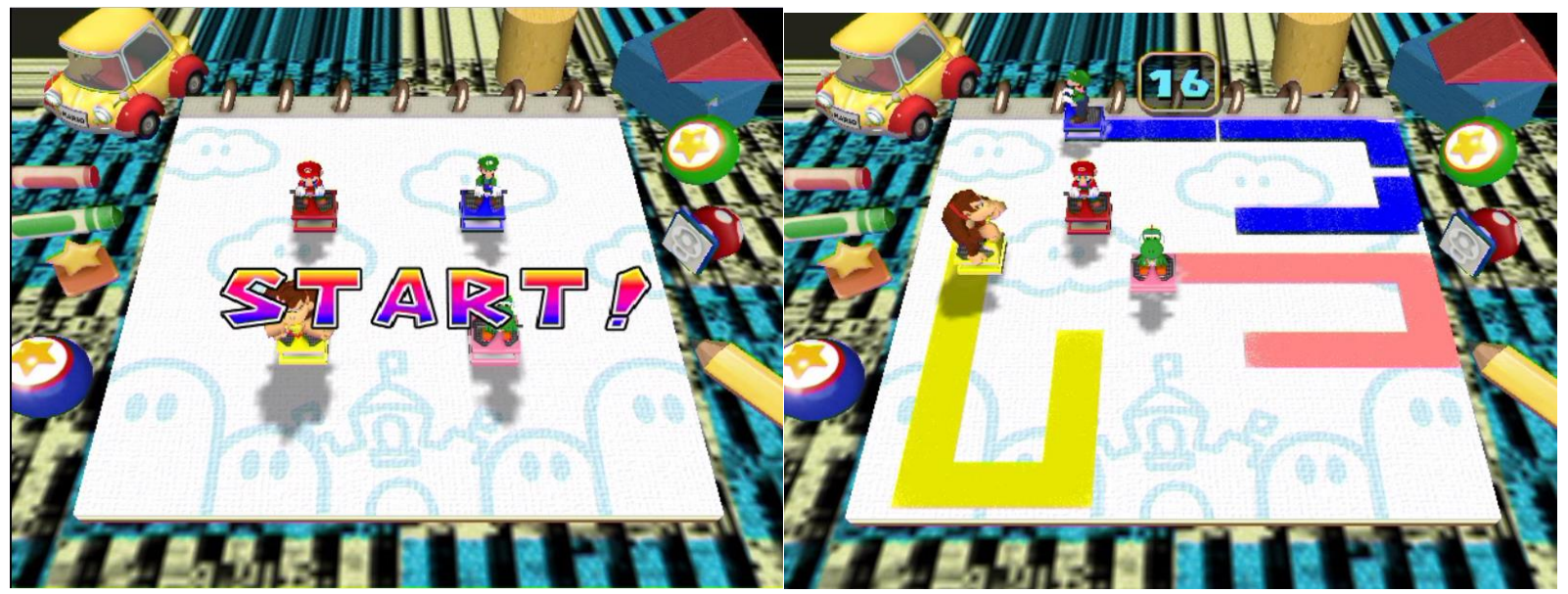

The participants start in the position seen above.

In the example above, all three active avatars do not wish to engage in sabotage

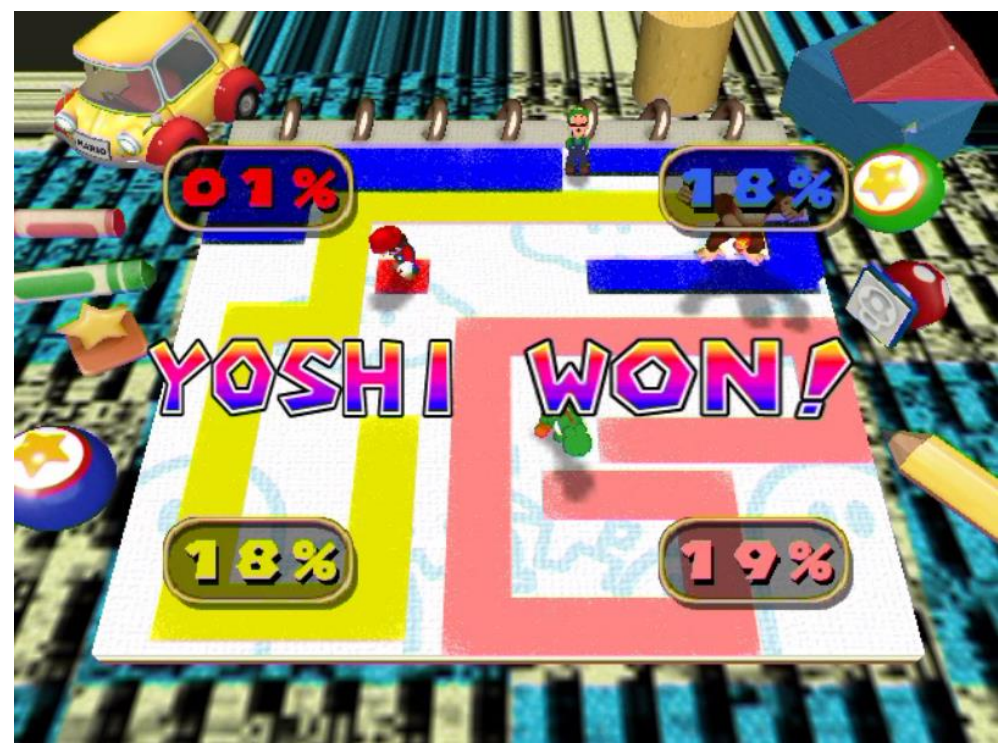

A total of $55 \%$ of the canvas was painted by the participants. As always, the red avatar (Mario) was controlled by the host computer and was inactive throughout the experiment. 
The task was performed in an experimental lab that contained a series of networked computers inside private cubicles. Although, the software was originally designed to support four networked players simultaneously performing the computerized task, participants were instead arranged into groups of three and assigned to computers that were networked into a fourth "host player". The fourth inactive host player was controlled by the experimenter. This allowed the experimenter to completely control the flow of the task, simultaneously monitor all activity, and better analyze the experiment.

All participants remain completely anonymous to each other, so that any behavior exhibited during the experiment is not influenced by prior relationships or fear of postexperimental reprisals. Each participant is separated from each other by cubicle dividers and avatars are positioned in an irregular arrangement. Additionally, in a post-experimental questionnaire, each participant was asked the following two questions:

Did you, at any time, know the true identity of anyone else's avatar?

YES NO, If yes, please explain how:

Did anyone else, at any time, know the true identity of your avatar?

YES NO, If yes, please explain how:

For each question, 177 out of 180 participants indicated that they and everyone else were completely anonymous ${ }^{6}$.

Participants were assigned an avatar and groups of three by utilizing covariate adaptive randomization $^{7}$ (Fleiss et al. 2003). Because prior research has associated gender with sabotage,

\footnotetext{
${ }^{6}$ The participants that indicated otherwise said they could hear "sighs" or sounds of excitement coming from another participant at the end of each match. Removing these data does not significantly affect the conclusions in this study.

${ }^{7}$ Because my sample size was relatively small, I had to make sure that any anticipated covariates (such as gender) were evenly balanced across conditions. I used random assignment unless this resulted in group that was composed of all one gender. If that happened, I randomly switched two participants between groups until each
} 
groups were initially randomly assigned, but rearranged if a group contained only one gender.

This was done in order to balance a potential covariate across conditions (Suresh 2011).

Although, the three active participants are asymmetrically arranged on the board, a postexperimental analysis of the task revealed that the initial starting position of the participant was not a significant predictor of sabotage $(\mathrm{p}=0.554$, two-tailed $)$.

After the instructions were given, the participants complete a short quiz that ensures they understand the instructions, including their economic incentives, the goal of painter crop, and how sabotage effected overall productivity. The participants are then told that, before officially starting the job, they would have to complete Painter Corp's training program. Each participant was given five training rounds. During training, they were told to "try their best" and were allowed to request personal help during this period. The training rounds were completed and recorded on a duplicate program that was pre-set for solo play (in which all other avatars are inactive). After five rounds of practice, they are switched over to the main program that is pre-set for networked play.

Next, the participants begin the recorded experimental group task for at least 10 rounds. At the end of the tenth round, a coin is flipped in order to determine if the experiment will include an additional round. This process is continued until the result of the coin flip determines that the experiment is over. The method that determines the number of total rounds played is explained during the initial instructions and is used in order to prevent "end game effects" (Schatzberg and Stevens 2008; Douthit et al. 2012).

After the final round of the experiment is over, the participants answer a postexperimental questionnaire, are paid anonymously in cash, and leave.

group had at least one of each gender. This method has an advantage over stratified randomization, in that it can balance the covariates even when the sample size is relatively small (Hu et al. 2014) 


\section{Independent Variables}

In my experiment, I controlled both the presence and absence of a code of ethics and the type of incentive compensation scheme (tournament / flat wage) utilized. The task was described along with how they will be compensated. In the "code" condition, after the practice period, immediately before the recorded task begins, the employees were presented with a single sheet of paper with the company's code of ethics:

As an employee, hired by the company, I am expected to adhere to the following:

- I will act in good faith with the intention to add value to the company through hard work and ethical conduct.

- I will act responsibly and ethically with regard to my fellow employees and will not seek personal gain at their expense.

This code of ethics is an adapted and simplified version of what would typically be seen in the workplace $^{8}$. Consistent with Pragmatic Theory of Language, by limiting the content in the code of ethics I help ensure message delivery and highlight its importance (Huang 2007; Bloomfield 2012). The participants were then required to certify this code of ethics by signing and dating the bottom of the page.

How the participants were to be economically incentivized was outlined in the experimental instructions and varied according to the experimental condition. The participants were paid in an experimental currency, Lira, denoted by the " $£$ " symbol. Under a flat wage incentive scheme, each participant was paid $£ 200$ per 30 second round regardless of production. Under the tournament incentive scheme, whoever has the highest percentage of the canvas

\footnotetext{
${ }^{8}$ The code of ethics was taken from the Manufacturers' Agents National Association (MANA) and adapted and simplified for the experimental procedure. See Appendix A.
} 
painted at the end of each 30 second round were paid $£ 400$. The other two participants were paid $£ 100$. In case of a tie, the two winners received $£ 250$ with the remaining participant receiving $£ 100$. In case of a three-way tie, all three participants would receive $£ 200$.

In addition, because the real effort task may resemble how some participants may spend their real life leisure time (playing a video game), the participants were also compensated for their inactivity during the task in order to better distinguish between effort and leisure. In all conditions, participants were told that they would be compensated $£ 2$ for every second of inactivity in a 30 second round (which could result in a maximum $£ 60$ bonus). This method of ensuring that effort is costly follows the lead of similar methods utilized in experimental accounting research (Sprinkle 2000; Hecht et al. 2012; Newman and Tafkov 2014). The instructions ended by telling participants that at the end of the experiment, a random round would be selected and the payoff for that round will be converted from Lira into Dollars at the predetermined exchange rate, so they should treat each round as the payoff round.

\section{Dependent Variables}

The task was video recorded on each group's "host" computer. Individual sabotage occurred when one employee painted over a portion of the canvas that had already been painted by another employee. Each video was carefully analyzed in order to correctly record the amount of sabotage that had been done by each avatar. The correlation between the two sabotage coders was 0.953 with a Cronbach's alpha of 0.973 , which exceeds typical reliability thresholds (Field 2013) ${ }^{9}$. Group Sabotage was calculated by recording the sum of all the individual sabotage that

\footnotetext{
${ }^{9}$ Such a high number isn't surprising considering that the coders that were rating sabotage were essentially engaging in slow, careful, counting rather than trying give a subjective assessment. See Appendix B for an excerpt from the sabotage coding instructions.
} 
occurred within the group during a 30 second round. Individual Redundancy Loss occurred when one employee was sabotaged by another employee. Group Redundancy Loss was calculated by recording the sum of all the individual redundancy loss that occurred within the group during a 30 second round. Because the canvas is a closed system, by definition Group Sabotage = Group Redundancy Loss. In other words, whenever one employee sabotaged another, an equal amount of sabotage and loss occurred within the group. Individual productivity was recorded as the percentage of the canvas that had been painted by the avatar's unique color at the end of the 30 second round. At the end of each round the computer program displayed the percentage of the canvas that was covered by each avatar and declared a winner. Group Productivity was calculated by recording the total percentage of the canvas that was covered by the three employees $^{10}$. Individual Effort ${ }^{11}$ was represented by the amount of canvas an employee would have been credited with painting (Individual Productivity) if redundancy loss due to sabotage from another employee had not occurred. Thus Individual Effort = Individual Productivity + Individual Redundancy Loss. Likewise Group Effort = Group Productivity + Group Redundancy Loss. Group Effort could also be calculated by recording the sum of all Individual Effort within the group. Individual Effort Withheld ${ }^{12}$ was recorded as the individual's highest effort recorded

\footnotetext{
${ }^{10}$ Although there were four avatars on the screen, the red avatar (Mario) was controlled by the host computer and was inactive throughout the experiment.

${ }^{11}$ Although keystrokes were recorded, they do not serve as a good proxy for effort because they only represent one reliable measured attribute of effort (duration). While the act of painting as much of the canvas as possible incorporates all four attributes of effort: direction, duration, intensity, and strategy development (Bonner and Sprinkle 2002).

${ }^{12}$ I am confident that individual learning did not confound this measure for two reasons (1) Only $6 \%$ of the recorded rounds have an avatar giving more effort than that of their highest recorded training round. (2) The round the participants were in was not a significant predictor of Individual Effort ( $p=0.849$, two-tailed).
} 
during the training rounds minus the individual effort recorded for that period. Group Effort Withheld was calculated as the sum of all the Individual Effort Withheld within the group.

\section{RESULTS}

\section{Participants}

A total of 180 student participants from a large southeastern university engaged in the experiment. Participants included 76 males and 104 females whose age ranged from 18 to 62 years old, with an average age of 22.7 years. The experiment lasted approximately 30 minutes for which participants received an average of $\$ 9.88^{13}$.

Test of H1

H1 predicted that, absent a code of ethics, employees will engage in more sabotage when compensated under a tournament incentive system than given a flat wage. Panel A of Table 1 gives the descriptive statistics of Group Effort Wasted due to Sabotage. My test results, shown in Panel B of Table 1, illustrated that those employed under a tournament incentive system engaged in more sabotage $(26.37 \%)$ than those given a flat wage $(20.24 \%)(\mathrm{p}<0.01$, one-tailed) which supports H1.

\footnotetext{
${ }^{13}$ The participants were informed that they could leave the experiment at any time and still receive a "show-up" fee of $\$ 5$.
} 


\section{Table 1}

\section{Panel A:}

\begin{tabular}{|c|c|c|c|}
\hline \multicolumn{2}{|c|}{ Descriptive Statistics } & & \\
\hline $\begin{array}{l}\text { Group Effort W } \\
\text { Sabota } \\
\text { mean (standar }\end{array}$ & iation) & \multicolumn{2}{|c|}{$\begin{array}{l}\text { Type of Incentive } \\
\text { Compensation }\end{array}$} \\
\hline \multirow{5}{*}{$\begin{array}{l}\text { Code of } \\
\text { Ethics }\end{array}$} & & Flat Wage & Tournament \\
\hline & \multirow{2}{*}{ No Code } & $\mathrm{n}=150$ & $\mathrm{n}=150$ \\
\hline & & $20.24 \%(13.32)$ & $26.37 \%(13.31)$ \\
\hline & \multirow{2}{*}{ Code } & $\mathrm{n}=150$ & $\mathrm{n}=150$ \\
\hline & & $11.61 \%(11.77)$ & $8.15 \%(8.88)$ \\
\hline
\end{tabular}

* Calculated as (Group Redudency Loss due to Sabotage / Group Effort), averaged across all 10 periods.

\section{Panel B:}

Test of Hl
\begin{tabular}{|lccc|}
\hline Hypothesis & Mean Difference & t-statistics & p-Value* \\
\hline $\begin{array}{l}\text { Dependent Variable - Sabotage } \\
\text { No Code / Tournament }>\text { No Code / Flat }\end{array}$ & 6.13 & 3.99 & $<0.01$ \\
\hline
\end{tabular}


Figure 2 presents a graph that shows the average amount of Group Redundancy Loss due to Sabotage that occurred each round under each treatment group.

\section{Figure 2}

\section{Mean Group Sabotage per Round}

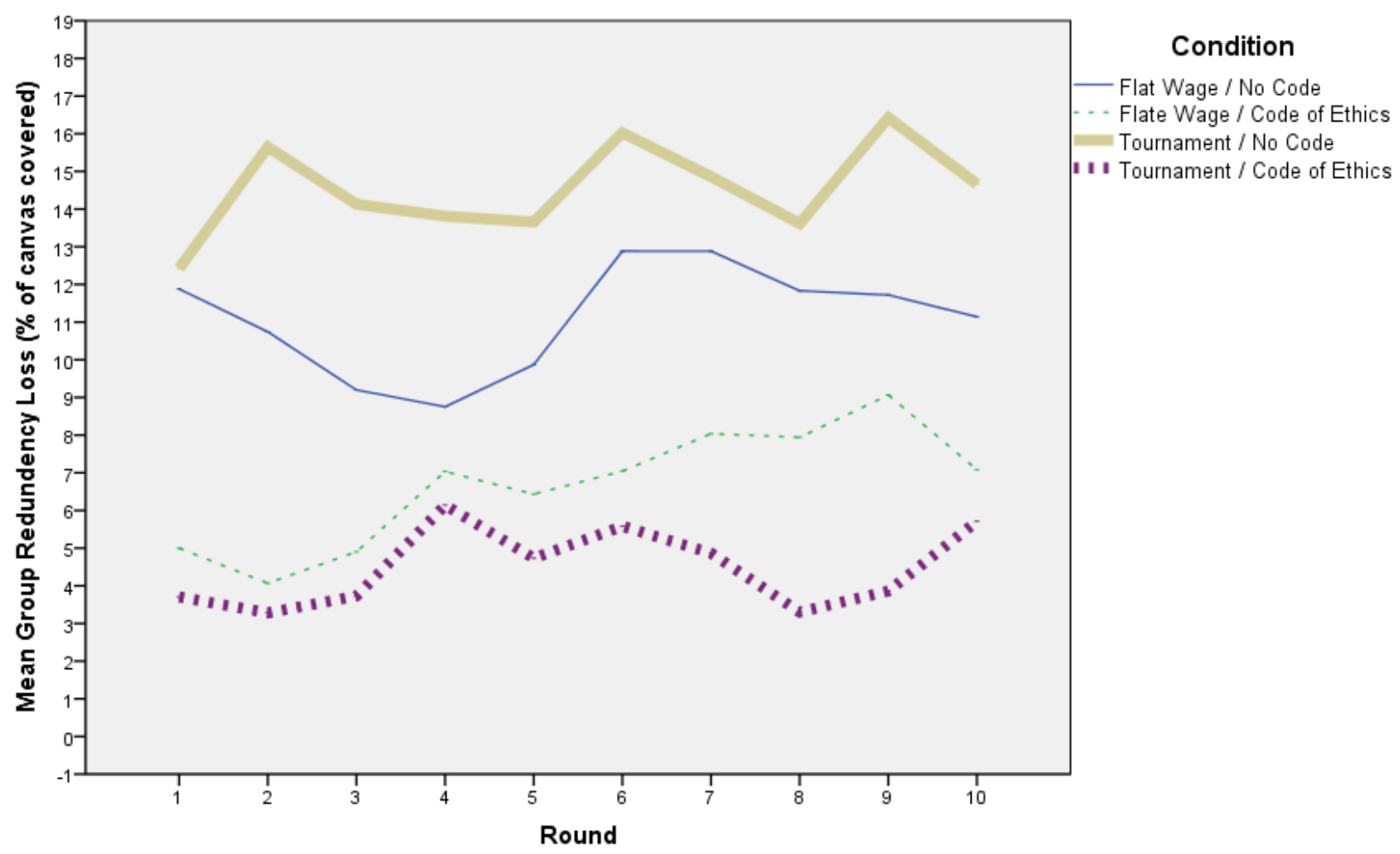

Test of $\mathrm{H} 2$

I directly test the participants normative and empirical expectation (via a postexperimental questionnaire) in order to both reaffirm the findings and illuminate the theoretical mechanism of Bicchieri's model (2006). In other words, in order to affirm that a code of ethics led to a change in behavior because of social norm activation, it is necessary to measure the mechanism by which a social norm is activated (the normative and empirical expectations of the participants). In a post-experimental questionnaire, the participants were asked to respond to a 
series of statements by utilizing a seven-point a Likert scale of 1 (strongly disagree) to 7

(strongly agree). Their response to the following statement tested their empirical expectations:

Before I started the task, I expected that the other employees would not paint over an area of the canvas that I had already painted.

Their response to the following statement tested their normative expectations:

Before the task began, the other employees expected me not to paint over an area of the canvas that they had already painted.

Table 2 gives the descriptive statistics for the responses to the questions testing the empirical and normative expectations respectively. Participants who certified a code of ethics, regardless of the incentive compensation type present, responded with an average Likert score that was significantly higher than 4 ( $<<0.01$, two-tailed) to both questions. On the other hand, the responses of those who had not certified a code of ethics, regardless of incentive compensation type present, were not significantly different than the middle Likert response of 4 . This shows that certifying a code of ethics leads to a significant measurable change in both empirical and normative expectations, which should lead to a change in behavior according to Bicchieri's model (2006). 


\section{Table 2}

\section{Descriptive statistics for PEQ measure of empirical and normative expectations (the process by which a social norm is activated)}

\begin{tabular}{|c|}
\hline Descriptive Statistics \\
\hline $\begin{array}{c}\text { Empirical Expectation PEQ: Before I started the task, I expected } \\
\text { that the other employees would not paint over an area of the } \\
\text { canvas that I had already painted }\end{array}$ \\
\hline mean (standard deviation) \\
\hline $\begin{array}{c}\text { P-value from a one sample t-test. } \\
\text { Hypothetical mean of } 4\end{array}$ \\
\hline
\end{tabular}

Type of Incentive

\begin{tabular}{c|c|c|c|}
\multicolumn{1}{c|}{} & \multicolumn{2}{c}{ Compensation } \\
\cline { 3 - 4 } & & Flat Wage & Tournament \\
\cline { 3 - 4 } & \multirow{4}{*}{$\begin{array}{c}\text { Node of } \\
\text { Ethics }\end{array}$} & $\mathrm{n}=45$ & $\mathrm{n}=45$ \\
\cline { 3 - 4 } & & $4.62(2.27)$ & $3.67(2.01)$ \\
\cline { 3 - 4 } & $\mathrm{p}=0.073$ & $\mathrm{p}=0.272$ \\
\hline \multirow{3}{*}{ Code } & $\mathrm{n}=45$ & $\mathrm{n}=45$ \\
\cline { 3 - 4 } & $5.47(0.97)$ & $5.60(0.96)$ \\
\cline { 3 - 4 } & $\mathrm{p}<0.001$ & $\mathrm{p}<0.001$ \\
\hline
\end{tabular}

*Answers were given on a 7 point Likert scale ranging from: Strongly Disagree (1) to Strongly Agree (7)

\begin{tabular}{|c|}
\hline Descriptive Statistics \\
\hline $\begin{array}{c}\text { Normative Expectation PEQ: Before the task began, the other } \\
\text { employees expected me not to paint over an area of the canvas } \\
\text { that they had already painted }\end{array}$ \\
\hline mean (standard deviation) \\
\hline P-value from a one sample t-test. \\
Hypothetical mean of 4
\end{tabular}

Type of Incentive Compensation

\begin{tabular}{|c|c|c|c|}
\hline & \\
\hline & & Flat Wage & Tournament \\
\hline \multirow{6}{*}{$\begin{array}{l}\text { Code of } \\
\text { Ethics }\end{array}$} & \multirow{3}{*}{ No Code } & $\mathrm{n}=45$ & $\mathrm{n}=45$ \\
\hline & & $4.44(1.87)$ & $4.02(1.83)$ \\
\hline & & $\mathrm{p}=0.117$ & $\mathrm{p}=0.935$ \\
\hline & \multirow{3}{*}{ Code } & $\mathrm{n}=45$ & $\mathrm{n}=45$ \\
\hline & & $5.36(1.00)$ & $5.73(0.96)$ \\
\hline & & $\mathrm{p}<0.001$ & $\mathrm{p}<0.001$ \\
\hline
\end{tabular}

*Answers were given on a 7 point Likert scale ranging from: Strongly Disagree (1) to Strongly Agree (7)

$\mathrm{H} 2$ predicted that having employees certify a code of ethics will have a larger effect on sabotage for those under tournament based compensation than those under piece rate or flat wage compensation. One of the reasons a code of ethics could also have less of an effect on sabotage when employees are given a flat wage is because it's easier to rationalize bad behavior (evade the norm) when there are no financial consequences (Tsang 2002). 


\section{Table 3}

\section{Panel A:}

\section{Repeated Measures ANCOVA on Individual Sabotage}

\begin{tabular}{|c|c|c|}
\hline Source of Variation & F-stat & p-value* \\
\hline \multicolumn{3}{|l|}{ Between Subjects } \\
\hline Code / No code & 54.95 & $<0.01$ \\
\hline Tournament / Flat Wage & 1.03 & 0.313 \\
\hline Code / No code ${ }^{*}$ Tournament / Flat Wage & 7.69 & $<0.01$ \\
\hline Gender (Covariate) & 13.77 & $<0.01$ \\
\hline Risk Preference (Covariate) & 1.17 & 0.281 \\
\hline Character / Position (Covariate) & 1.64 & 0.202 \\
\hline \multicolumn{3}{|l|}{ Within Subjects } \\
\hline Round & 0.875 & 0.547 \\
\hline Round * Gender & 0.577 & 0.817 \\
\hline Round * Risk Preference & 0.569 & 0.823 \\
\hline Round $*$ Character / Position & 0.978 & 0.456 \\
\hline Round * Tournament / Flat Wage & 1.29 & 0.237 \\
\hline Round $*$ Code / No Code & 1.59 & 0.111 \\
\hline Round * Code / No Code * Tournament / Flat Wage & 0.865 & 0.557 \\
\hline
\end{tabular}

I first estimate a repeated measures ANCOVA in Panel A of Table 3 for which the dependent variable is Individual Sabotage and which analyzes Code / No Code and Tournament / Flat Wage between subjects and Round within subjects while controlling for the individual effects of the participants' gender, avatar/position, and measured risk preferences ${ }^{14}$. Because gender is the only

\footnotetext{
${ }^{14}$ Risk preferences were measured using an simplified form of a lottery choice task in which the participants could choose between a $50 \%$ chance of receiving $\$ 2$ or $100 \%$ chance of receiving $\$ 1$ (Holt and Laury 2002; Hales et al. 2014)
} 
significant covariate in Panel A, I retain it as a covariate in Panel $\mathrm{B}^{15}$ of Table 3 in which I estimate a repeated measures ANCOVA for which the dependent variable is Group Redundancy Loss due to Sabotage and which tests the same between and within subjects factors as Panel A.

\section{Table 3 (continued)}

\section{Panel B:}

\section{Repeated Measures ANCOVA on Group Loss due to Sabotage}

\begin{tabular}{l} 
Source of Variation \\
\hline Between Subjects \\
Code / No code \\
Tournament / Flat Wage \\
Code / No code * Tournament / Flat Wage \\
Gender (Covariate)
\end{tabular}

Within Subjects

$\begin{array}{lll}\text { F-stat } & & \text { p-value }^{*} \\ & & \\ 90.16 & & <0.01 \\ 0.825 & & 0.365 \\ 13.18 & & <0.01 \\ 2.12 & & 0.147\end{array}$

$1.36 \quad 0.201$

$0.261 \quad 0.985$

$3.17<0.01$

$3.43<0.01$

$2.06 \quad 0.03$

*two-tailed

As predicted by H2, I find a significant Code / No Code x Tournament / Flat Wage interaction (F $=7.69, \mathrm{p}<0.01)$. Figure 3 illustrates the disordinal interaction.

\footnotetext{
${ }^{15}$ In Panel B, Gender, measured as the number of males in the group is not a significant covariate of Group Redundancy Loss. This indicates that my use of covariate adaptive randomization successfully mitigated the effects of gender as a potential covariate on Group Activity.
} 
Figure 3

The Interactive Effect of Compensation Type and Code of Ethics
Certification on Productivity Loss due to Sabotage

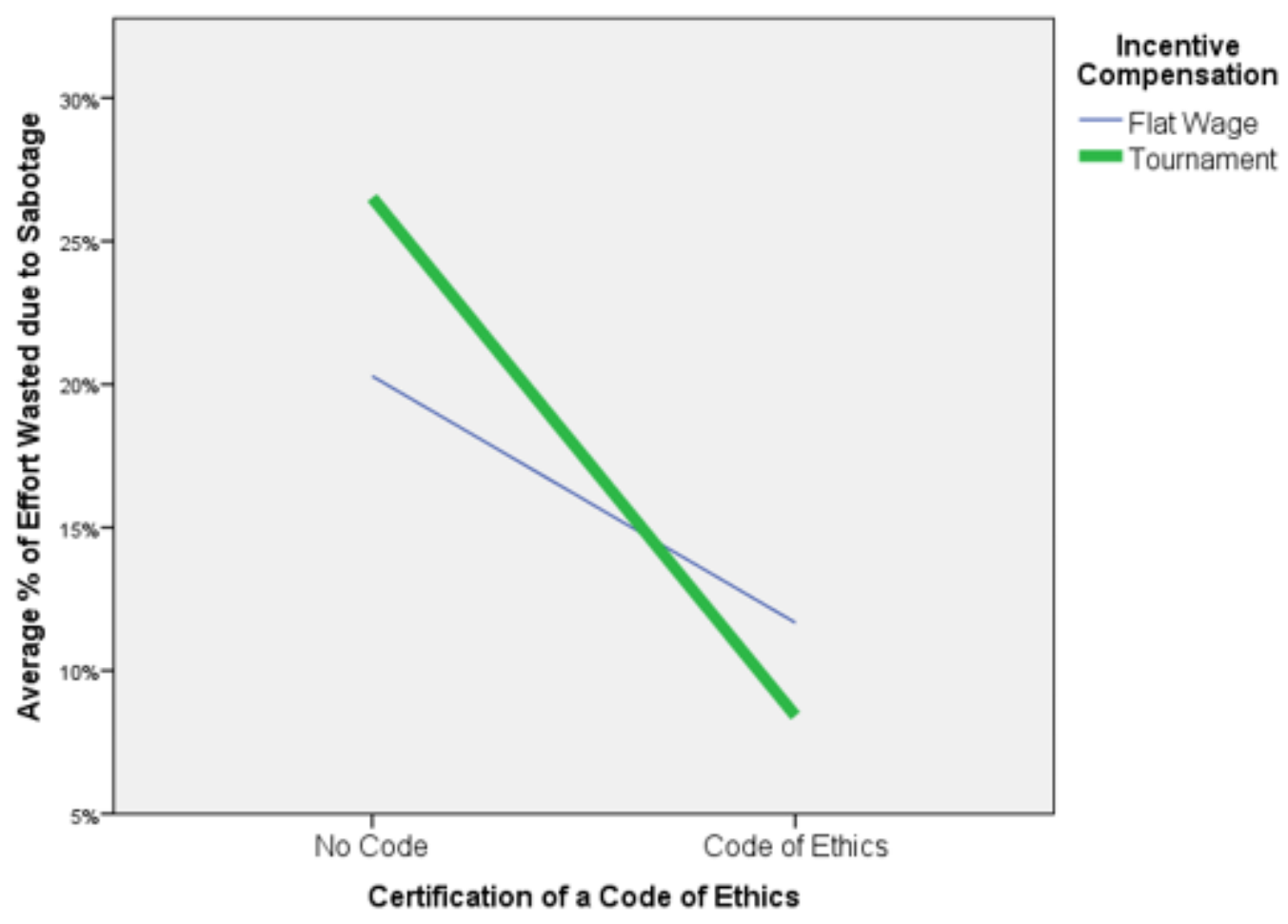

Test of $R Q 1$

RQ1 aims to explore the effects of the incentive scheme and the certification of a code of ethics on overall productivity. In other words, which combination would result in the highest level of productivity? Recall that Productivity is the result of both Effort and Sabotage. In addition, because Sabotage cannot only hinder current productivity, but also discourage future effort, Group Effort Withheld was measured in an attempt to capture discouragement. Panel A of Table 4 the descriptive statistics of Group Productivity. 


\section{Table 4}

\section{Panel A:}

\begin{tabular}{|c|c|c|c|}
\hline \multicolumn{2}{|c|}{ Descriptive Statistics } & & \\
\hline $\begin{array}{l}\text { Group Prod } \\
\text { mean (standard }\end{array}$ & $\begin{array}{l}\text { ty*: } \\
\text { lation) }\end{array}$ & \multicolumn{2}{|c|}{$\begin{array}{l}\text { Type of Incentive } \\
\text { Compensation }\end{array}$} \\
\hline \multirow{5}{*}{$\begin{array}{l}\text { Code of } \\
\text { Ethics }\end{array}$} & & Flat Wage & Tournament \\
\hline & \multirow{2}{*}{ No Code } & $\mathrm{n}=150$ & $\mathrm{n}=150$ \\
\hline & & $43.25(8.50)$ & $40.39(8.26)$ \\
\hline & \multirow{2}{*}{ Code } & $\mathrm{n}=150$ & $\mathrm{n}=150$ \\
\hline & & $48.72(7.39)$ & $49.63(8.48)$ \\
\hline
\end{tabular}

* The units for the numbers above are the percentage of the canvas painted, averaged across all 10 periods.

Flat Wage*Code and Tournament*Code were the two conditions with the highest level of average Group Productivity (with $48.72 \%$ and $49.63 \%$ of the canvas covered respectively). The difference between these two conditions is not significant ( $\mathrm{p}=0.323$, two-tailed) and these two conditions are higher than both the Flat Wage * No Code $(\mathrm{p}<0.01$, two-tailed $)$ and the Tournament $*$ No Code condition $(\mathrm{p}<0.01$, two-tailed). Curiously, those in the Tournament $*$ Code condition reported the highest variance for Effort, and Effort Withheld. 


\section{Table 4 (continued)}

\section{Panel B:}

\begin{tabular}{|c|c|c|}
\hline \multicolumn{3}{|c|}{ Repeated Measures ANCOVA on Group Productivity } \\
\hline Source of Variation & F-stat & p-value ${ }^{*}$ \\
\hline \multicolumn{3}{|l|}{ Between Subjects } \\
\hline Code / No code & 58.525 & $<0.01$ \\
\hline Tournament / Flat Wage & 1.03 & 0.311 \\
\hline Code / No code * Tournament / Flat Wage & 3.85 & 0.05 \\
\hline Gender (Covariate) & 0.001 & 0.971 \\
\hline \multicolumn{3}{|l|}{ Within Subjects } \\
\hline Round & 0.463 & 0.9 \\
\hline Round * Gender & 0.488 & 0.884 \\
\hline Round * Tournament / Flat Wage & 1.376 & 0.193 \\
\hline Round * Code / No Code & 6.61 & $<0.01$ \\
\hline Round * Code / No Code * Tournament / Flat Wage & 2.798 & $<0.01$ \\
\hline
\end{tabular}

In Panel B of Table 4, I estimated a repeated measures ANCOVA for which the dependent variable is Group Productivity and which analyzes Code / No Code and Tournament / Flat Wage between subjects and Round within subjects while controlling for Gender. The certification of a code of ethics has a significant main effect ( $\mathrm{p}<0.01$ two-tailed); However, there is also a significant interaction between Code of Ethics Certification and Compensation Incentive used ( $\mathrm{p}<0.01$, two-tailed). Figure 4 illustrates this interaction. 


\section{Figure 4}

\section{The Interactive Effect of Compensation Type and Code of Ethics}

Certification on Group Productivity

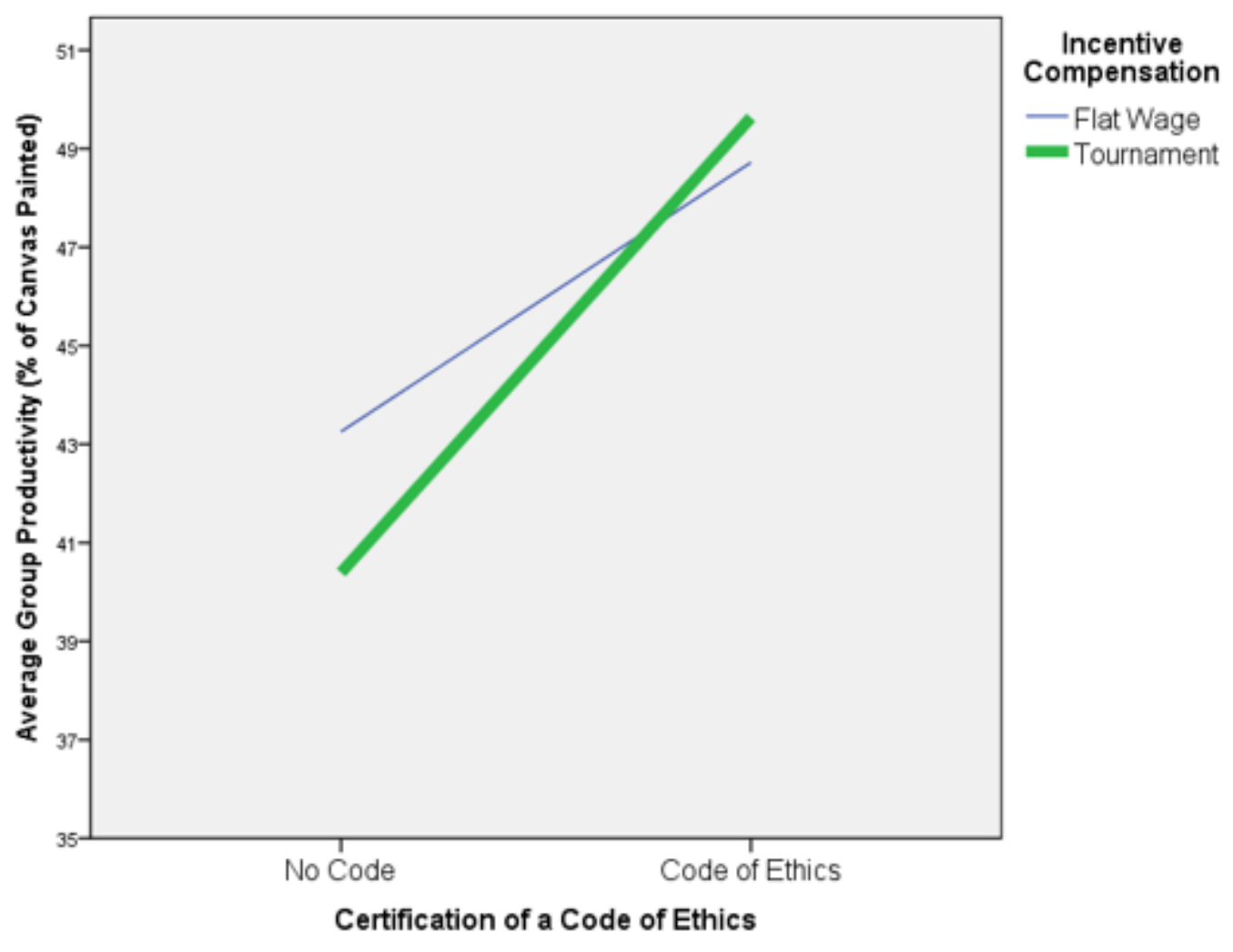

After further investigation, I discovered that the high variances in Effort, and Effort Withheld reported in the Tournament * Code condition could be explained by how strongly that group became discouraged as a result of sabotage. 


\section{Table 5}

\section{Panel A:}

\begin{tabular}{|c|}
\hline Descriptive Statistics \\
\hline \begin{tabular}{c} 
Discouragement Measure PEQ: \\
The behavior of others discouraged me from trying my best \\
mean (standard deviation) \\
\hline P-value from a one sample t-test with a hypothetical mean of 4. \\
All p-values are two tailed.
\end{tabular} \\
\hline
\end{tabular}

Type of Incentive Compensation

\begin{tabular}{c|c|c|c|}
\cline { 3 - 4 } \multicolumn{1}{c|}{} & Flat Wage & Tournament \\
\cline { 3 - 4 } \multicolumn{1}{c|}{$\begin{array}{c}\text { Code of } \\
\text { Ethics }\end{array}$} & $\mathrm{n}=45$ & $\mathrm{n}=45$ \\
\cline { 3 - 4 } & & $3.58(1.97)$ & $4.36(1.90)$ \\
\cline { 3 - 4 } & $\mathrm{p}=0.160$ & $\mathrm{p}=0.210$ \\
\hline \multirow{3}{*}{ Code } & $\mathrm{n}=45$ & $\mathrm{n}=45$ \\
\cline { 3 - 4 } & $3.69(1.95)$ & $4.71(1.84)$ \\
\hline & $\mathrm{p}=0.292$ & $\mathrm{p}=0.013$ \\
\hline
\end{tabular}

* Answers were given on a 7 point Likert scale ranging from: Strongly Disagree (1) to Strongly Agree (7)

Panel A of Tables 5 shows the descriptive statistics for the response to the post-experimental question designed to capture discouragement. The participants were asked to respond to the following question by utilizing a seven-point a Likert scale of 1 (strongly disagree) to 7 (strongly agree).

The behavior of others discouraged me from trying my best

Despite the fact that those in the Tournament $*$ Code condition experienced the least amount of sabotage, their response to that post experiment question, $4.71(\mathrm{p}=0.013)$, indicates they were the only condition that felt any level of discouragement as a result of sabotage. Their behavior also indicates discouragement. 


\section{Table 5 (continued)}

\section{Panel B:}

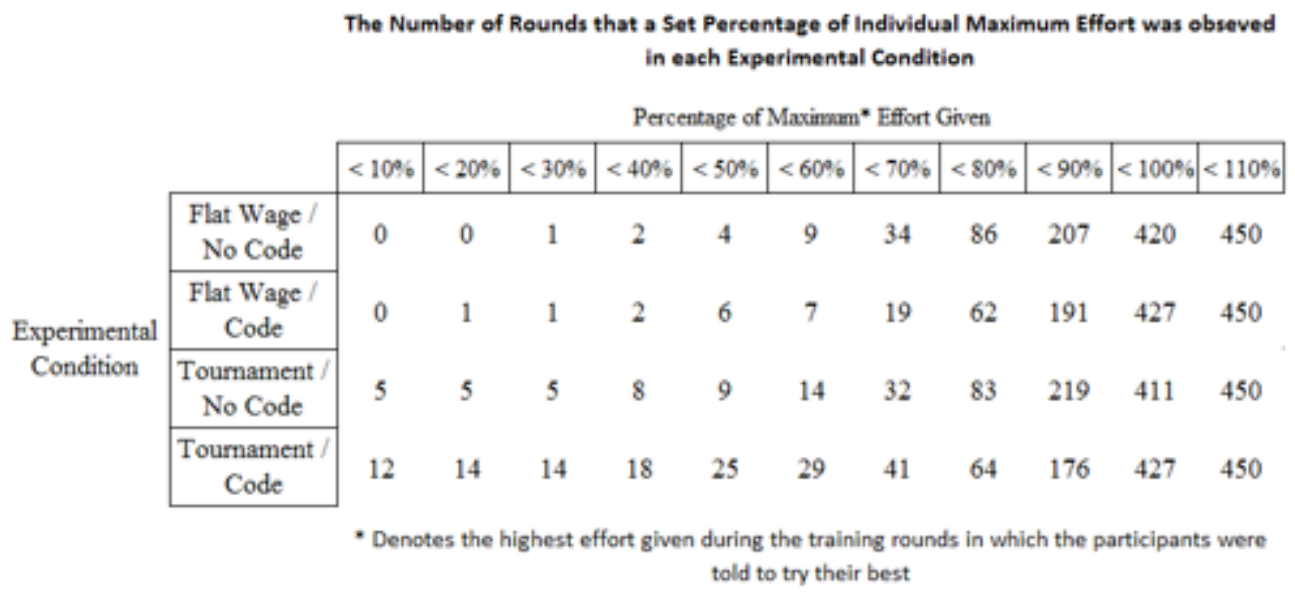

Panel B of Table 5 displays the number of rounds an individual participant exhibited a particular level of effort by condition. I assign the highest level of effort given during the individual training rounds (in which they were told to "try their best", as the participant's maximum effort. I then divided their individual effort during the test rounds by this maximum in order to see if they were giving their best effort throughout the experiment. Panel B of Table 5 shows that there 25 individual occurrences in the Tournament * Code condition where the participants gave less than $50 \%$ of the potential maximum effort. In those instances, it could be said that they simply "gave up". Compare this to the 4, 6, and 9 times this occurred in the other conditions. There were 12 occurrences were participants gave less than $10 \%$ of their maximum effort in the Tournament $*$ No Code condition compared to 5 occurrences in the Tournament No Code condition and 0 occurrences in the other two conditions. Simply put, those participants who had experienced sabotage after certifying a code of ethics under tournament compensation were more likely to be so uniquely discouraged that, unlike those in the other conditions, they subsequently exerted little to no effort and dragged down the mean Group Effort and Group Productivity for the rest of those in the same experimental condition. 


\section{Other Social Norms Activated}

I assert that any change in behavior caused by the certification of a code of ethics would happen because the social norm of promise keeping would be activated as predicted by Bicchieri's model (2006) of social norm activation. However, simply publically agreeing to act "ethically" (as is the case in my study) may activate any number of other social norms including fairness, reciprocity, and trustworthiness. In my post-experimental questionnaire, I attempt to find out what other social norms are activated when my participants certified a code of ethics.

\section{Table 6}

\section{Panel A:}

\begin{tabular}{|c|c|c|c|}
\hline \multicolumn{4}{|c|}{ Descriptive Statistics } \\
\hline \multicolumn{4}{|c|}{$\begin{array}{c}\text { Promise Keeping Norm Activation PEQ: } \\
\text { My behavior was based on my desire to keep my promise }\end{array}$} \\
\hline \multicolumn{4}{|c|}{ mean (standard deviation) } \\
\hline \multicolumn{4}{|c|}{$\begin{array}{l}\text { P-value from a one sample t-test with a hypothetical mean of } 4 . \\
\qquad \text { All p-values are two tailed. }\end{array}$} \\
\hline \multirow{8}{*}{$\begin{array}{l}\text { Code of } \\
\text { Ethics }\end{array}$} & & \multicolumn{2}{|c|}{$\begin{array}{l}\text { Type of Incentive } \\
\text { Compensation }\end{array}$} \\
\hline & & Flat Wage & Tournament \\
\hline & \multirow{3}{*}{ No Code } & $\mathrm{n}=45$ & $\mathrm{n}=45$ \\
\hline & & $4.46(1.62)$ & $3.66(1.79)$ \\
\hline & & $\mathrm{p}=0.063$ & $\mathrm{p}=0.209$ \\
\hline & \multirow{3}{*}{ Code } & $\mathrm{n}=45$ & $\mathrm{n}=45$ \\
\hline & & $5.16(1.54)$ & $5.51(1.24)$ \\
\hline & & $\mathrm{p}<0.01$ & $\mathrm{p}<0.01$ \\
\hline
\end{tabular}

* Answers were given on a 7 point Likert scale ranging from: Strongly Disagree (1) to Strongly Agree (7)

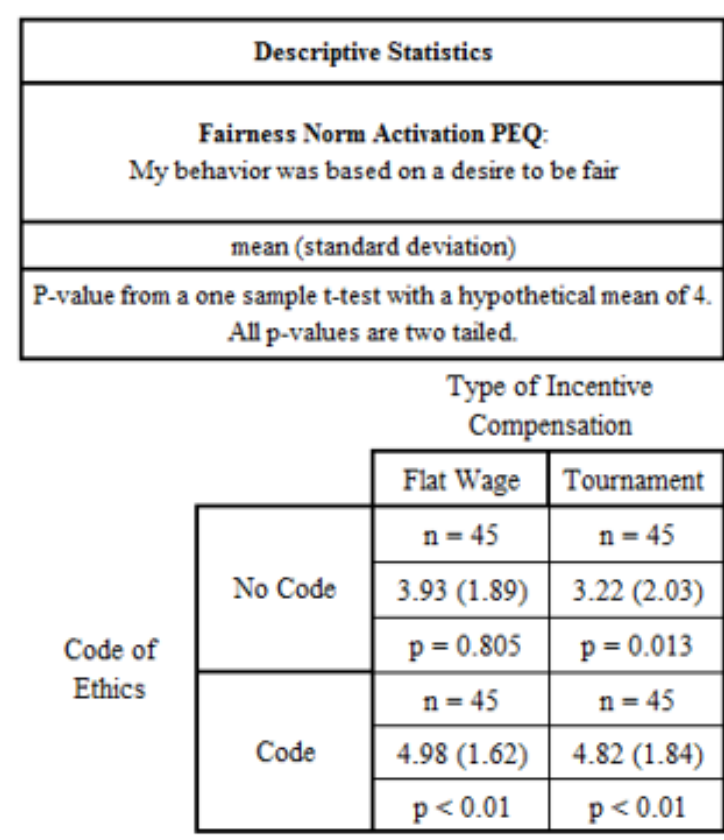

* Answers were given on a 7 point Likert scale ranging from: Strongly Disagree (1) to Strongly Agree (7) 
Promise Keeping. On Panel A of Table 6, I first measure the social norm activation of promise keeping the by asking participants to respond to the following statement using a seven-point a Likert scale of 1 (strongly disagree) to 7 (strongly agree):

My behavior was based on my desire to keep my promise As expected, those participants who certified a code of ethics gave an average response of 5.15 which is significantly higher than the middle value of 4 ( $p<0.01$, two-tailed). By contrast, those who did not certify a code of ethics gave an average response of 4.07 , which was not significantly different than the middle value of 4 ( $p=0.718$, two-tailed). Thus indicating that certifying a code of ethics specifically led to a promise keeping norm activation.

Fairness. I next measure the activation of the social norm of fairness by asking participants to respond to the following statement using a seven-point a Likert scale of 1 (strongly disagree) to 7 (strongly agree):

My behavior was based on my desire to be fair Again, the participants who certified a code of ethics gave an average response of 4.90, which is significantly higher than the middle value of 4 ( $\mathrm{p}<0.01$, two-tailed). Those under the tournament condition, who did not certify a code of ethics gave an average response of 3.22, which was significantly lower than the middle value of 4 ( $\mathrm{p}=0.013$, two-tailed). Thus indicating that a desire to be fair did not affect their behavior. While, those in the Flat Wage * No Code condition gave an average response of 3.93, which was not significantly different than $4(p=0.805$, twotailed). 


\section{Table 6 (continued)}

\section{Panel B:}

\begin{tabular}{|c|}
\hline Descriptive Statistics \\
\hline $\begin{array}{c}\text { Reciprocity Norm Activation PEQ: } \\
\text { My behavior was based on my desire to reciprocate the } \\
\text { behavior of others }\end{array}$ \\
\hline mean (standard deviation) \\
\hline $\begin{array}{c}\text { P-value from a one sample t-test with a hypothetical mean of } 4 . \\
\text { All p-values are two tailed. }\end{array}$ \\
\hline
\end{tabular}

Type of Incentive Compensation

\begin{tabular}{|c|c|c|c|}
\hline & & & \\
\hline & & Flat Wage & Tournament \\
\hline \multirow{6}{*}{$\begin{array}{l}\text { Code of } \\
\text { Ethics }\end{array}$} & \multirow{3}{*}{ No Code } & $\mathrm{n}=45$ & $\mathrm{n}=45$ \\
\hline & & $4.56(1.79)$ & $4.70(2.08)$ \\
\hline & & $p=0.042$ & $\mathrm{p}=0.029$ \\
\hline & \multirow{3}{*}{ Code } & $\mathrm{n}=45$ & $\mathrm{n}=45$ \\
\hline & & $4.29(2.02)$ & $4.84(1.72)$ \\
\hline & & $p=0.341$ & $p<0.01$ \\
\hline
\end{tabular}

* Answers were given on a 7 point Likert scale ranging from: Strongly Disagree (1) to Strongly Agree (7)

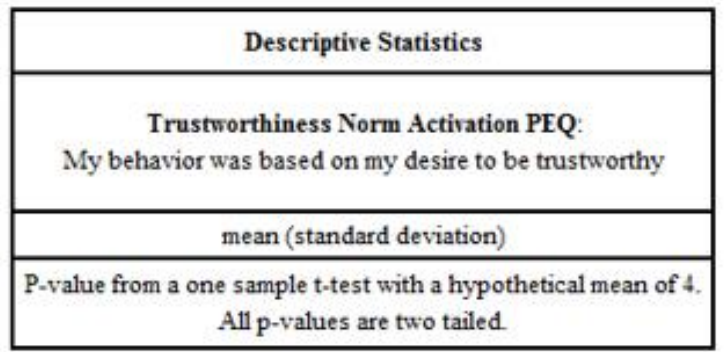

Type of Incentive Compensation

\begin{tabular}{|c|c|c|c|}
\hline & \\
\hline & & Flat Wage & Tournament \\
\hline \multirow{6}{*}{$\begin{array}{l}\text { Code of } \\
\text { Ethics }\end{array}$} & \multirow{3}{*}{ No Code } & $\mathrm{n}=45$ & $\mathrm{n}=45$ \\
\hline & & $4.07(1.80)$ & $3.13(1.98)$ \\
\hline & & $p=0.795$ & $\mathrm{p}<0.01$ \\
\hline & \multirow{3}{*}{ Code } & $\mathrm{n}=45$ & $\mathrm{n}=45$ \\
\hline & & $4.98(1.82)$ & $4.84(1.69)$ \\
\hline & & $p<0.01$ & $p<0.01$ \\
\hline
\end{tabular}

* Answers were given on a 7 point Likert scale ranging from: Strongly Disagree (1) to Strongly Agree (7)

Reciprocity. Panel B of Table 6 shows the results of reciprocity norm activation, which I measure by asking participants to respond to the following statement using a seven-point a Likert scale of 1 (strongly disagree) to 7 (strongly agree):

My behavior was based on my desire to reciprocate the behavior of others This time, the participants who did not certify a code of ethics gave an average response of 4.63 which is significantly higher than the middle value of 4 ( $p<0.01$, two-tailed). This is not surprising, given the amount of sabotage that took place under those conditions and how instinctual and ubiquitous the norm of revenge / negative reciprocity is (Lillie and Strelan 2016). Those under the flat wage * code condition, gave an average response of 4.29 , which was not 
significantly different than the middle value of 4 ( $p=0.341$, two-tailed). While those in the Tournament $*$ Code condition gave an average response of 4.84 , which was significantly higher than 4 ( $\mathrm{p}=0.805$, two-tailed). Given the low amount of sabotage present in that condition, this might indicate that their behavior was influenced by a desire to exhibit positive reciprocity.

Trustworthiness. Finally, I measure the activation of the social norm of trustworthiness by asking participants to respond to the following statement using a seven-point a Likert scale of 1 (strongly disagree) to 7 (strongly agree):

My behavior was based on my desire to be trustworthy.

The responses mirror that of the fairness norm. The participants who certified a code of ethics gave an average response of 4.91 , which is significantly higher than the middle value of 4

$(\mathrm{p}<0.01$, two-tailed). Those in the Tournament $*$ No Code condition, gave an average response of 3.13, which was significantly lower than the middle value of 4 ( $p=0.013$, two-tailed). Thus indicating that a desire to be trustworthy did not affect their behavior. While, those in the Flat Wage * No Code condition gave an average response of 4.07 , which was not significantly different than 4 ( $\mathrm{p}=0.795$, two-tailed).

As Bicchieri’s (2006) model allows for, my code of ethics appeared to have, indeed, activated several social norms, namely, promise keeping, fairness, and trustworthiness. Conversely, the social norm of reciprocity did not appear to need code of ethics certification to be activated.

\section{CONCLUSION}

I study the effectiveness of a code of ethics on sabotage, effort, and productivity under two different incentive systems, namely fixed wage and tournament. Tournaments are often used 
because of their ability to attract top talent, reduce environmental risk, and motivate employees to give their best effort (Lazear and Rosen 1981b; Grote 2005; McGregor 2006; Ng and Lublin 2010). However, because the incentive structure explicitly evokes competition, employees may be reluctant to cooperate and might even engage in strategic behavior such as sabotage (Lazear 1989; Harbring and Irlenbusch 2011; Dato and Nieken 2014).

The remedies suggested to reduce sabotage involve reducing the economic incentives that contribute to both beneficial and harmful behavior (Chen 2003). In the accounting literature to date, no remedy for the harmful effects of a tournament incentive has been investigated because the ability to sabotage has been restricted by way of tight experimental control. I utilize an experiment in which participants perform a real effort task which allows them to sabotage each other and receive relative performance feedback in real-time. I examine a very attractive form of sabotage: overtly stealing credit from fellow employees. This often talks place in the workplace and can effect raises and promotion decisions (Uzzi and Dunlap 2012; Dillon 2014). I chose to study this attractive form of sabotage because any remedy I found would also presumably work on less attractive, forms of sabotage, such as costly destruction. I manipulated the presence or absence of a code of ethics (that condemns sabotage) and the type of incentive compensation used (tournament / flat wage) in order to examine their effects on individual employee behavior and overall firm productivity. I first predict that sabotage during a tournament will be higher than fixed pay because of the higher incentive to sabotage during a tournament. I employ Bicchieri's (2006) model of social norm activation to make applicable predictions that advance theory related to harmful behavior such as sabotage and ways to control such behavior in the firm. I predict and find that by employing a code of ethics, I can activate the social norm of promise keeping which discourages those in a tournament from engaging in sabotage, while still giving 
their best effort. However, I discover this might not work in all cases. In a minority of cases, I discover that if in which sabotage persists under a tournament in spite of a code of ethics, participants become more discouraged than they would otherwise.

I propose to extend the literature by demonstrating a way to reduce the negative effects of sabotage under tournament based compensation. In addition, by utilizing real effort tasks with real-time relative performance feedback and allowing for sabotage, I can examine the effect with increased ecological validity. Furthermore, although competition-induced sabotage has been shown to be a problem under a tournament incentive scheme when allowed, as of yet no solution has been proposed which can reduce this potential shortcoming of tournament incentives. In addition, by directly measuring the participants normative and empirical expectations, I also hope to extend prior literature by further exploring the underlying mechanisms that manage Bicchieri's model of social norm activation, which models social norms in a way that can be readily incorporated within traditional agency theory while utilizing current research in social norms from the behavioral literature.

This study also has potential implications for practice. The results of this study suggest that if companies truly want to activate a social norm that would assuage negative behavior, like sabotage, that they should not simply adopt a code of ethics for regulatory compliance. They should, instead, implement a system in which ground level employees certify the code of ethics that discourages such behavior.

Further studies could explore how to combat acts of covert sabotage which, according to Biccheri's Model, would be particularly equipped to evade social norms activated by a code of ethics because these acts would be unobservable. In addition, because I suspect the findings of this study would not generalize to sabotage directed at employers, further research could also explore 
the effectiveness this and other remedies of stopping sabotage directed at the employer's company rather than his coworkers. Also, subsequent studies could also explore the cause and cures for workplace discouragement that was evident in this study.

I hope to provide management with insight into how to practically design and implement an incentive system. Special care may be needed to protect team members from those who's personality classifies them as inherently resistant to social norms, such as a those who may border on schizoid personality disorder (Triebwasser et al. 2012). However, it's very possible that by having employees certify a code of ethics while competing in a tournament might be a way for management to get the "best of both worlds". 


\section{References}

Abbink, K., and B. Herrmann. 2011. THE MORAL COSTS OF NASTINESS. Economic Inquiry 49 (2):631-633.

Abbink, K., and A. Sadrieh. 2009. The pleasure of being nasty. Economics Letters 105 (3):306308.

Abdel-Rahim, H. Y., and D. E. Stevens. 2015. The Effect of Information System Precision on Honesty in Manigerial Reporting: A Systematic Re-Examination. Working Paper.

Ambrose, M. L., M. A. Seabright, and M. Schminke. 2002. Sabotage in the workplace: The role of organizational injustice. Organizational Behavior and Human Decision Processes 89 (1):947-965.

Analoui, F. 1995. Workplace sabotage: its styles, motives and management. Journal of Management Development 14 (7):48-65.

Backes-Gellner, U., and K. Pull. 2013. Tournament compensation systems, employee heterogeneity, and firm performance. Human Resource Management 52 (3):375-398.

Balafoutas, L., F. Lindner, and M. Sutter. 2012. Sabotage in Tournaments: Evidence from a Natural Experiment. Kyklos 65 (4):425-441.

Benson, G. C. S. 1989. Codes of Ethics. Journal of Business Ethics 8 (5):305-319.

Berger, L., K. J. Klassen, T. Libby, and A. Webb. 2013. Complacency and Giving Up Across Repeated Tournaments: Evidence from the Field. Journal of Management Accounting Research 25 (1):143-167.

Bicchieri, C. 2006. The grammar of society : the nature and dynamics of social norms / Cristina Bicchieri: Cambridge ; New York : Cambridge University Press, 2006. 
Blay, A., E. Gooden, M. Mellon, and D. E. Stevens. 2015. The Usefulness of Social Norm Theory in Empirical Business Ethics Research: A Review and Some Experimental Evidence in an Audit Market Setting. Working Paper.

Bloomfield, R. J. 2012. A pragmatic approach to more efficient corporate disclosure. Accounting Horizons 26 (2):357-370.

Bodolica, V., and M. Spraggon. 2015. An Examination into the Disclosure, Structure, and Contents of Ethical Codes in Publicly Listed Acquiring Firms. Journal of Business Ethics $126(3): 459-472$.

Bol, J. C., and J. B. Lill. 2015. Performance Target Revisions in Incentive Contracts: Do Information and Trust Reduce Ratcheting and the Ratchet Effect? Accounting Review 90 (5):1755-1778.

Bonner, S. E., and G. B. Sprinkle. 2002. The effects of monetary incentives on effort and task performance: theories, evidence, and a framework for research. Accounting Organizations and Society 27 (4-5):303-345.

Carpenter, J., P. H. Matthews, and J. Schirm. 2010. Tournaments and Office Politics: Evidence from a Real Effort Experiment. American Economic Review 100 (1):504-517.

Casas-Arce, P., and F. A. Martínez-Jerez. 2009. Relative performance compensation, contests, and dynamic incentives. Management Science 55 (8):1306-1320.

Charness, G., D. Masclet, and M. C. Villeval. 2014. The dark side of competition for status. Management Science 60 (1):38-55.

Chen, K. P. 2003. Sabotage in promotion tournaments. Journal of Law Economics \& Organization 19 (1):119-140. 
Cleek, M. A., and S. L. Leonard. 1998. Can corporate codes of ethics influence behavior? Journal of Business Ethics 17 (6):619-630.

Crino, M. D. 1994. Employee Sabotage: A Random Or Preventable Phenomenon? Journal of Managerial Issues 6 (3):311-330.

Dato, S., and P. Nieken. 2014. Gender differences in competition and sabotage. Journal of Economic Behavior \& Organization 100:64-80.

Davidson, B. I., and D. E. Stevens. 2013. Can a Code of Ethics Improve Manager Behavior and Investor Confidence? An Experimental Study. The Accounting Review 88 (1):51-74.

del Corral, J., J. Prieto-Rodriguez, and R. Simmons. 2010. The effect of incentives on sabotage: The case of Spanish football. Journal of Sports Economics 11 (3):243-260.

Dillon, K. 2014. HBR Guide to Office Politics: Harvard Business Review Press.

Dohmen, T., A. Falk, K. Fliessbach, U. Sunde, and B. Weber. 2011. Relative versus absolute income, joy of winning, and gender: Brain imaging evidence. Journal of Public Economics 95 (3-4):279-285.

Douthit, J. D., L. W. Kearney, and D. E. Stevens. 2012. Can Agent Cheap Talk Mitigate Agency Problems in the Presence of a Noisy Performance Measure? An Experimental Test in a Single- and Multi-Period Setting. Journal of Management Accounting Research 24 (1):135-158.

Field, A. 2013. Discovering statistics using IBM SPSS statistics: Sage.

Fleiss, J. L., B. Levin, and M. C. Park. 2003. A statistical Methods for Rates and Proportion. . 3rd ed ed. Hoboken NJ:: John Wiley and Sons.

Grote, R. C. 2005. Forced ranking:Making performance managment work: Havard Business School Press. 
Gupta, A. K., and A. Singhal. 1993. Managing human resources for innovation and creativity. Research Technology Management 36 (3):41.

Gürtler, O., J. Münster, and P. Nieken. 2013. Information Policy in Tournaments with Sabotage Scandinavian Journal of Economics 115 (3):932-966.

Hales, J., L. W. Wang, and M. G. Williamson. 2014. Selection benefits of stock-based compensation for the rank-and-file. The Accounting Review 90 (4):1497-1516.

Hannan, R. L., R. Krishnan, and A. H. Newman. 2008. The effects of disseminating relative performance feedback in tournament and individual performance compensation plans. Accounting Review 83 (4):893-913.

Harbring, C., and B. Irlenbusch. 2005. Incentives in tournaments with endogenous prize selection. Journal of Institutional and Theoretical Economics (JITE)/Zeitschrift für die gesamte Staatswissenschaft:636-663.

Harbring, C., and B. Irlenbusch. 2008. How many winners are good to have? On tournaments with sabotage. Journal of Economic Behavior \& Organization 65 (3-4):682-702.

Harbring, C., and B. Irlenbusch. 2011. Sabotage in tournaments: Evidence from a laboratory experiment. Management Science 57 (4):611-627.

Hecht, G., I. V. O. Tafkov, and K. L. Towry. 2012. Performance Spillover in a Multitask Environment*. Contemporary Accounting Research 29 (2):563-589.

Helin, S., and J. Sandstrom. 2007. An inquiry into the study of corporate codes of ethics. Journal of Business Ethics 75 (3):253-271.

Holt, C. A., and S. K. Laury. 2002. Risk aversion and incentive effects. American Economic Review 92 (5):1644-1655. 
Hu, F., Y. Hu, Z. Ma, and W. F. Rosenberger. 2014. Adaptive randomization for balancing over covariates. Wiley Interdisciplinary Reviews: Computational Statistics 6 (4):288-303.

Huang, Y. 2007. Pragmatics. Oxford, U.K.: Oxford University Press.

Jamal, K., and N. Bowie. 1995. Theoretical considerations for a meaningful code of professional ethics. Journal of Business Ethics 14 (9):703-714.

Jeter, S. J., and G.-W. U. S. o. Nursing. 2010. Sabotage and Workplace Bullying: The Bad and Ugly of Horizontal Violence: Gardner-Webb University.

Kaptein, M., and M. S. Schwartz. 2008. The effectiveness of business codes: A critical examination of existing studies and the development of an integrated research model. Journal of Business Ethics 77 (2):111-127.

Komic, D., S. L. Marusic, and A. Marusic. 2015. Research Integrity and Research Ethics in Professional Codes of Ethics: Survey of Terminology Used by Professional Organizations across Research Disciplines. Plos One 10 (7):13.

KPMG. 2008. Business Codes for the Global 200: Their Prevelance, Content and Embedding. The Netherlands: KMPG.

Lazear, E., and S. Rosen. 1981a. Rank-Order Tournaments as Optimum Labor Contracts. Journal of political economy (5):841.

Lazear, E. P. 1989. Pay equality and industrial politics. Journal of political economy:561-580.

Lazear, E. P., and S. Rosen. 1979. Rank-order tournaments as optimum labor contracts: National Bureau of Economic Research Cambridge, Mass., USA.

Lazear, E. P., and S. Rosen. 1981b. Rank-Order Tournaments as Optimum Labor Contracts. 841. 
Lewis, C. S. 1952. Mere Christianity: a revised and amplified edition, with a new introduction, of the three books, Broadcast talks, Christian behaviour, and Beyond personality: G. Bles.

Lillie, M., and P. p. s. a. e. a. Strelan. 2016. Careful what you wish for: Fantasizing about revenge increases justice dissatisfaction in the chronically powerless. Personality \& Individual Differences 94:290-294.

Maher, B. 2010. SABOTAGE! Nature 467 (7315):516-518.

McGregor, J. 2006. The struggle to measure performance. Business Week:26-28.

McKendall, M., B. DeMarr, and C. Jones-Rikkers. 2002. Ethical compliance programs and corporate illegality: Testing the assumptions of the corporate sentencing guidelines. Journal of Business Ethics 37 (4):367-383.

Münster, J. 2007. Selection Tournaments, Sabotage, and Participation. Journal of Economics \& Management Strategy 16 (4):943-970.

NADA. 2015. NADA Dealership Workforce Study: National Automobile Dealership Association.

Newman, A. H., and I. D. Tafkov. 2014. Relative performance information in tournaments with different prize structures. Accounting Organizations and Society 39 (5):348-361.

Ng, S., and J. Lublin. 2010. AIG pay plan: Rank and file. The Wall Street Journal.

Nintendo. 2002. Mario Party 4. Kyoto, Japan: Nintendo Co., Ltd.

Okada, R. 1955. Japanese Proverbs and Proverbial Phrases. Tokyo: Japan Travel Bureau.

Pierce, M. A., and J. W. Henry. 1996. Computer ethics: The role of personal, informal, and formal codes. Journal of Business Ethics 15 (4):425-437. 
Prendergast, C. 1999. The Provision of Incentives in Firms. Journal of Economic Literature 37 (1):7.

Schatzberg, J. W., and D. E. Stevens. 2008. Public and Private Forms of Opportunism within the Organization: A Joint Examination of Budget and Effort Behavior. Journal of Management Accounting Research 20:59-81.

Schwartz, M. 2001. The nature of the relationship between corporate codes of ethics and behaviour. Journal of Business Ethics 32 (3):247-262.

Singh, J. 2011. Determinants of the Effectiveness of Corporate Codes of Ethics: An Empirical Study, 385-395.

Smith, A. 1759/1790. The Theory of Moral Sentiments: Oxford University Press, 1976.

Somers, M. J. 2001. Ethical codes of conduct and organizational context: A study of the relationship between codes of conduct, employee behavior and organizational values. Journal of Business Ethics 30 (2):185-195.

SOX, U. S. H. o. R. 2002. The Sarbanes-Oxley Act of 2002. Public Law 107-204 [H.R. 3763]. Washington, DC: Government Printing Office.

Sprinkle, G. B. 2000. The Effect of Incentive Contracts on Learning and Performance. The Accounting Review 75 (3):299-326.

Sprouse, M., and T. Illustrator-Cox. 1992. Sabotage in the American workplace: Anecdotes of dissatisfaction, mischief and revenge: Pressure Drop Press.

Stajkovic, A. D., and A. D. Luthans. 1997. Business ethics across cultures: A social cognitive model. Journal of World Business 32 (1):17-34.

Stevens, B. 1994. AN ANALYSIS OF CORPORATE ETHICAL CODE STUDIES - WHERE DO WE GO FROM HERE. Journal of Business Ethics 13 (1):63-69. 
Suls, J. E., and T. A. E. Wills. 1991. Social comparison: Contemporary theory and research: Lawrence Erlbaum Associates, Inc.

Suresh, K. P. 2011. An overview of randomization techniques: An unbiased assessment of outcome in clinical research. Journal of Human Reproductive Sciences 4 (1):8-11.

Svensson, G., G. Wood, J. Singh, and M. Callaghann. 2009. Implementation, communication and benefits of corporate codes of ethics: an international and longitudinal approach for Australia, Canada and Sweden. Business Ethics-a European Review 18 (4):389-407.

Tafkov, I. D. 2013. Private and Public Relative Performance Information under Different Compensation Contracts. Accounting Review 88 (1):327-350.

Triebwasser, J., E. Chemerinski, P. Roussos, and L. J. Siever. 2012. Schizoid personality disorder. Journal of personality disorders 26 (6):919.

Tsang, J.-A. 2002. Moral Rationalization and the Integragtion of Situational Factors and Psychological Process in Immoral Behavior. Review of General Psychology 6 (1):23-50.

Uzzi, B., and S. Dunlap. 2012. Make Your Enemies Your Allies. Harvard business review 90 (5):133-135, 137, 151.

van Dijk, F., J. Sonnemans, and F. van Winden. 2001. Incentive systems in a real effort experiment. European Economic Review 45 (2):187-214.

Wotruba, T. R., L. B. Chonko, and T. W. Loe. 2001. The impact of ethics code familiarity on manager behavior. Journal of Business Ethics 33 (1):59-69. 


\section{Appendix A}

\section{The Sales Agency's Responsibilities to the Manufacturer/Principal:}

- To comply with the Principal's terms and conditions of sale.

- To conscientiously cover the assigned territory, accounts or industry segment.

- To avoid any form of misrepresentation.

- To establish relationships only with those Principals which will be well represented by the Sales Agency.

- To refrain from representing competing lines without written agreement of the Principal.

- To constantly strive to add value to the relationship between the Principal and the Customers.

\section{The Manufacturer's/Principal's Responsibilities to the Sales Agency:}

- To enter into a fair, clearly worded, written Sales Representative (Independent Contractor) Agreement which addresses the needs, concerns, expectations and objectives of both parties.

- To refrain from modifying the terms of this agreement, except by mutual written consent following full discussion of the matter.

- To recognize the Sales Agency as an important element in the sales goals of the Principal.

- To constantly strive to support the Sales Agency's efforts by timely responses and open communication.

\section{The Sales Agency's Responsibilities to the Customer:}

- To promote only those products or services which are in the Customer's best interest.

- To constantly strive to improve the relationship between the Principal and the Customer.

- To clearly and fairly communicate the needs of all parties in the business relationship.

- To process Customer problems and questions promptly and accurately.

\section{The Responsibilities of one Sales Agency to Another:}

- To share ideas beneficial to the rep profession.

- To respect existing Principal relationships of other Sales Agencies.

- To refrain from using unfair methods to solicit the Customers of another Sales Agency.

- To cooperate to enhance the professional relationship of the Sales Agency and its Principals by supporting MANA, which was established for that purpose; subscribing to its aims and objectives, and in every practical way working to advance the marketing interests of all Sales Agencies and their Principals.

\section{https://www.manaonline.org/about/code-of-ethics/}




\section{Appendix B: Excerpt from Sabotage Coding Instructions}

\section{How to Record Sabotage}

Think of the video you are about to watch as taking place on a $12 \times 12$ square meter canvas (see below). There are four avatars on the canvas, each with a $1 \times 1$ meter colored ink stamp. Each avatar can jump to a blank spot on the canvas and color that spot their unique color. Each avatar may jump anywhere from $\sim 0.3$ to $\sim 1.3$ meters. Your job is to record the amount canvas that is painted by each avatar that has already been colored by another avatar.

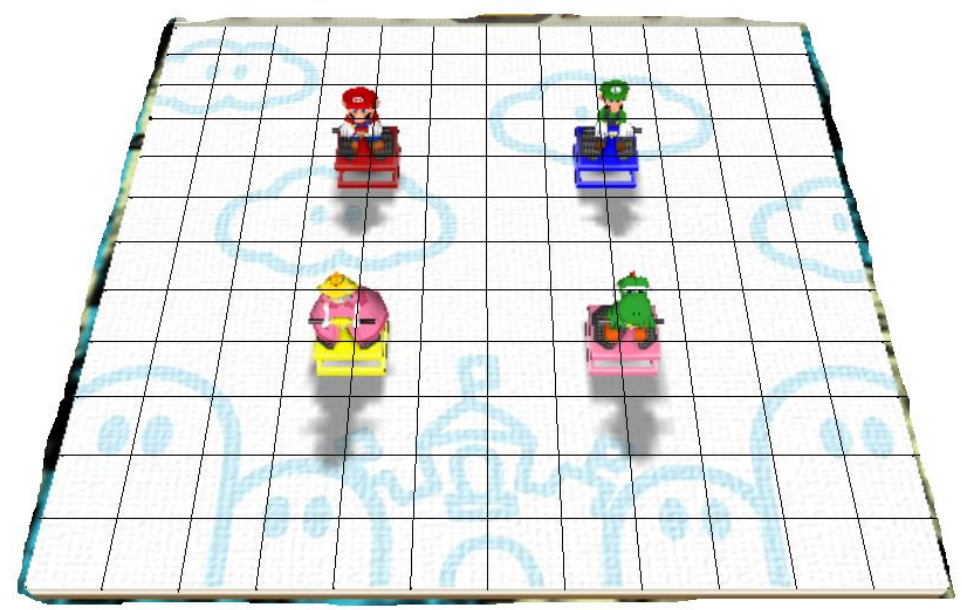

\begin{tabular}{|c|c|c|c|c|c|}
\hline $\begin{array}{l}\text { Number } \\
\text { of } 1 \times 1 \\
\text { squares }\end{array}$ & $\begin{array}{c}\% \text { of } \\
\text { Canvas } \\
\text { Covered }\end{array}$ & $\begin{array}{l}\text { Number } \\
\text { of } 1 \times 1 \\
\text { squares }\end{array}$ & $\begin{array}{c}\% \text { of } \\
\text { Canvas } \\
\text { Covered }\end{array}$ & $\begin{array}{c}\text { Number } \\
\text { of } 1 \times 1 \\
\text { squares }\end{array}$ & $\begin{array}{c}\% \text { of } \\
\text { Canvas } \\
\text { Covered }\end{array}$ \\
\hline 1 & $0.69 \%$ & 11 & $7.64 \%$ & 21 & $14.58 \%$ \\
\hline 2 & $1.39 \%$ & 12 & $8.33 \%$ & 22 & $15.28 \%$ \\
\hline 3 & $2.08 \%$ & 13 & $9.03 \%$ & 23 & $15.97 \%$ \\
\hline 4 & $2.78 \%$ & 14 & $9.72 \%$ & 24 & $16.67 \%$ \\
\hline 5 & $3.47 \%$ & 15 & $10.42 \%$ & 25 & $17.36 \%$ \\
\hline 6 & $4.17 \%$ & 16 & $11.11 \%$ & 26 & $18.06 \%$ \\
\hline 7 & $4.86 \%$ & 17 & $11.81 \%$ & 27 & $18.75 \%$ \\
\hline 8 & $5.56 \%$ & 18 & $12.50 \%$ & 28 & $19.44 \%$ \\
\hline 9 & $6.25 \%$ & 19 & $13.19 \%$ & 29 & $20.14 \%$ \\
\hline 10 & $6.94 \%$ & 20 & $13.89 \%$ & 30 & $20.83 \%$ \\
\hline
\end{tabular}




\section{Appendix B (continued): Excerpt from Sabotage Coding Instructions}

If an avatar paints over an area of the canvas that has previously been colored by another avatar, the amount painted is to be recorded as Sabotage. The amount of color that is now gone because it has been painted over by a new color is to be recorded as Loss. Please use a chart like the one below to keep track of which avatars have sabotaged whom.

\begin{tabular}{|c|c|c|c|c|}
\hline & & \multicolumn{3}{|c|}{ Sabotage } \\
\hline & & Luigi & DK & Yoshi \\
\hline \multirow{3}{*}{ Loss } & Luigi & & & \\
\hline & DK & & & \\
\hline & Yoshi & & & \\
\hline
\end{tabular}

For example, in the picture below, the pink avatar (Yoshi) has sabotage a 1x1 meter square area that was previously painted by the yellow avatar (DK).

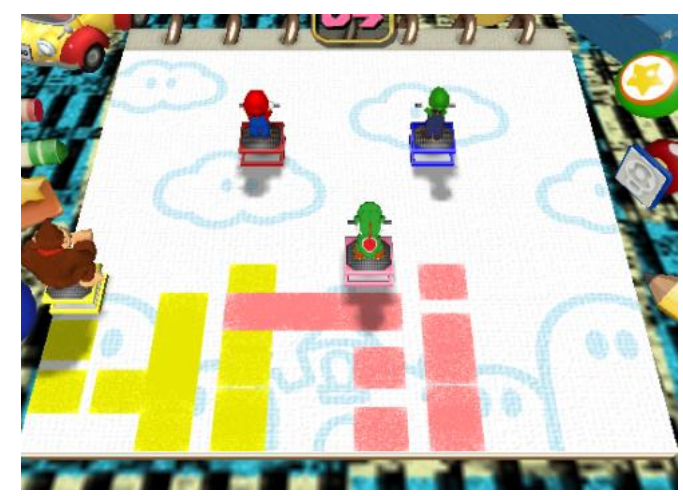

In this case, you would fill in the chart as one square of sabotage for Yoshi and one square of loss for DK.

\begin{tabular}{|c|c|c|c|c|}
\hline & & \multicolumn{3}{|c|}{ Sabotage } \\
\hline & & Luigi & DK & Yoshi \\
\hline \multirow{3}{*}{ Loss } & Luigi & & & \\
\hline & DK & & & 1 \\
\hline & Yoshi & & & \\
\hline
\end{tabular}

You will most likely need to re-watch the videos and focus on only one avatar at a time in order to get an accurate measurement. Please code your final recording as a $\%$ of the canvas (using the conversion chart above) rounded to the nearest percentage point. 